NBER WORKING PAPER SERIES

\title{
DOES MEDICAID PAY TOO MUCH FOR PRESCRIPTION DRUGS? A CASE STUDY OF ATYPICAL ANTI-PSYCHOTICS
}

\author{
Mark G. Duggan \\ Working Paper 9626 \\ http://www.nber.org/papers/w9626 \\ NATIONAL BUREAU OF ECONOMIC RESEARCH \\ 1050 Massachusetts Avenue \\ Cambridge, MA 02138 \\ April 2003
}

I am grateful to Alberto Abadie, Catalina Amuedo-Dorantes, David Autor, Gary Becker, Ernst Berndt, Hoyt Bleakley, Jeanette Chung, David Cutler, Bill Evans, Richard Frank, Sherry Glied, Austan Goolsbee, Michael Greenstone, Steven Levitt, Frank Lichtenberg, Will Manning, David Meltzer, Kevin Murphy, Fiona ScottMorton, and to seminar participants at Princeton, the University of British Columbia, the University of Chicago, and the NBER Health Care meetings for helpful comments at various stages of this project. Thanks also to Abby Alpert for outstanding research assistance, to the Robert Wood Johnson Foundation for financial support, and to Jim Klein from the California Department of Health Services for assistance with the Medicaid claims data. All errors are my own. The views expressed herein are those of the authors and not necessarily those of the National Bureau of Economic Research.

(C2003 by Mark G. Duggan. All rights reserved. Short sections of text not to exceed two paragraphs, may be quoted without explicit permission provided that full credit including Onotice, is given to the source. 
Does Medicaid Pay Too Much for Prescription Drugs? A Case Study of Atypical AntiPsychotics

Mark G. Duggan

NBER Working Paper No. 9626

April 2003

JEL No. H51, H57, H72, I11, I18, D61

\begin{abstract}
During the last several years, government spending on drugs used to treat schizophrenia and other psychotic illnesses has increased at more than 30\% per year, with the $\$ 3$ billion in 2001 Medicaid expenditures exceeding spending in any other therapeutic category. This growth has been primarily driven by a shift to atypical anti-psychotic drugs, which are several times more expensive than the conventional anti-psychotics that preceded them and are purchased almost exclusively by state governments through the Medicaid program. In this paper, I estimate the productivity of these new drugs using a 5\% sample of California Medicaid recipients eligible for the program in at least one month between January of 1993 and December of 2001 and diagnosed with schizophrenia during that period. My results indicate that the shift to atypical anti-psychotics has significantly increased government spending, has not reduced the utilization of hospitals or long-term care facilities, and has not improved observable measures of health among Medicaid recipients. The findings suggest that the price of a prescription drug purchased differentially by consumers with Medicaid or other public health insurance may be an inaccurate measure of it value to patients.
\end{abstract}

Mark G. Duggan

Department of Economics

University of Chicago

1126 East $59^{\text {th }}$ Street, Room 508

Chicago, IL 60637

and NBER

mduggan@midway.uchicago.edu 


\section{Introduction}

Approximately 44 million low-income individuals qualify for health insurance through the federal-state Medicaid program during the course of a typical year. Individuals eligible for the program receive coverage for hospital stays, physician visits, nursing home care, prescription drugs, and most other health care services. Because Medicaid recipients bear no financial cost for their medical care, standard moral hazard considerations imply that the benefits of some of the services covered by this program may fall substantially below their costs. With Medicaid spending currently at $2.5 \%$ of GDP, expenditures projected to grow significantly more rapidly than GDP in the coming decade, and federal and state governments confronting large budget deficits, policymakers may soon need to more carefully scrutinize whether the benefits of government spending on medical care justify the costs.

In this paper, I investigate the effect of on one category of treatments from the most rapidly growing component of Medicaid spending - prescription drugs. From 1996 to 2001, Medicaid spending on prescription drugs approximately doubled and now exceeds $\$ 25$ billion per year. This growth was driven primarily by a significant increase in the average price of a prescription, which itself was caused by a shift to new drugs rather than an increase in the price of existing drugs. The surge in spending was especially striking for drugs used to treat mental disorders, with expenditures increasing from \$2.0 billion in 1996 to $\$ 6.0$ billion in $2001{ }^{1}$

The 470 million prescriptions filled for Medicaid recipients in 2001 accounted for more than $15 \%$ of the 3.1 billion prescriptions filled nationally. This "Medicaid market share" varies substantially across therapeutic categories and has generally been increasing within these categories over time. Because of the formula that the government uses to determine the prices that it pays for Medicaid-insured prescriptions, it is likely that prices in the private market are significantly higher than they otherwise would be. This is likely to be especially true for those drugs consumed differentially by price-inelastic Medicaid consumers.

In addition to influencing the price of particular drugs, Medicaid coverage will distort recipients' decisions about which drugs to purchase. Because they bear no cost for their treatments, Medicaid recipients will tend to pick (or their physicians will recommend) the drug

\footnotetext{
${ }^{1}$ Preliminary data suggest that spending on drugs for the treatment of mental disorders increased to more than $\$ 7$ billion in 2002. As a reference, spending on this one category of prescription drugs therefore exceeds total spending by the federal government for job training programs, which equaled $\$ 6.7$ billion in that same year (U.S. Department of Labor, 2003).
} 
that offers the highest expected health benefit, even if it costs much more than a drug that would yield a similar increment to health. It is therefore ultimately an empirical question whether the sharp increase in government spending on prescription drugs has led to improvements in health or reductions in other health care utilization that justify the additional spending.

To examine this issue, I consider the impact of a sharp increase in government spending for anti-psychotic drugs - the therapeutic category with more Medicaid spending than any other for a large sample of Medicaid recipients diagnosed with schizophrenia. In 2001, nearly $80 \%$ of anti-psychotic prescriptions were filled for Medicaid recipients, making it the therapeutic category with the largest Medicaid market share. ${ }^{2}$ The average amount paid by Medicaid for an anti-psychotic prescription increased by a factor of five from $\$ 36$ in 1993 to $\$ 180$ in $2001 .^{3}$ This increase was almost entirely driven by a shift to Zyprexa, Risperdal, and Seroquel, three new drugs that were approved by the FDA for the treatment of schizophrenia during the mid-1990s and are now first, second, and eighth, respectively, with respect to total Medicaid spending. These three "atypical anti-psychotic" drugs are considered by some to have a more positive impact on cognition and a better side effect profile than the conventional anti-psychotics that preceded them, though this is controversial. ${ }^{4}$

Estimating the impact of these drugs using observational data is challenging because the treatments are not randomly assigned, and may therefore be correlated with an individual's (perhaps partially unobserved) health status. Thus the randomized clinical trials required for FDA approval are in some respects superior to any study that uses observational data. However, there are a number of limitations to these clinical trials. First, they do not investigate the effect on health care costs, instead only considering certain dimensions of health and typically comparing the drug only with a placebo rather than substitute drugs. Second, the clinical trials typically consider just short-term outcomes, examining those taking atypical anti-psychotics for a period of four to eight weeks. Third, the sample sizes used in the clinical trials of these drugs are much smaller than the number that I have in my data, and thus I can obtain more precise estimates of the effect of the drugs on outcome variables of interest (e.g. side effects that occur

\footnotetext{
${ }^{2}$ The next largest customer for this category of prescription drugs is the federal government, which purchases drugs for individuals insured by the Veterans' Health Administration. This program also has no co-pay for prescription drugs.

${ }^{3}$ All dollar amounts are adjusted to 2001 dollars using the CPI-U series from the Bureau of Labor Statistics.
} 
infrequently). Fourth, the individuals who participate in these trials may be quite different from the typical person who takes the drug following FDA approval. And finally, my data allow me to exploit variation over time in the diffusion of the drug and at a point-in-time across providers (e.g. psychiatrists) in the propensity to prescribe certain drugs, thus allowing me to estimate the effect of the drug on the marginal patient (which may change over time as the drugs diffuse) rather than simply the average treatment effect that is estimated in the trials.

In this paper, I use an administrative data set with claims and eligibility information for a 5\% sample of California's Medicaid recipients and employ three strategies for estimating the effect of the new anti-psychotic drugs on both health outcomes and on health care spending. ${ }^{5}$ I begin by estimating individual fixed effects specifications that measure the change in spending and health for schizophrenia patients who begin taking each drug shortly after its FDA approval. This strategy exploits variation across Medicaid recipients both in the decision to take the drug and in the time when the first prescription is taken. My findings demonstrate that the shift to Risperdal, Zyprexa, and Seroquel was associated with a sharp and significant increase in Medicaid spending but appeared to have little impact on health, as measured by the probability of hospitalization, the amount of time spent in the hospital, or the incidence of adverse side effects. If anything, the results suggest that health outcomes decline following the shift to the new drugs, as the incidence of diabetes is significantly greater after schizophrenia patients shift to Risperdal, Zyprexa, or Seroquel.

One important limitation of this first estimation strategy is that the shift to atypical antipsychotic drugs may - for many Medicaid recipients - be caused by a change in health. If this is the case, then the individual fixed effects analysis will confound the effect of the drugs with this other factor. My finding that the probability of hospitalization is trending up in the months leading up to Medicaid recipients' first atypical anti-psychotic prescription suggests that the individual fixed effects estimates are likely to be biased.

In an effort to surmount this problem, in my second estimation strategy I use a cohort analysis that compares the pre-post trajectory of outcome variables of interest for hospitalized

\footnotetext{
${ }^{4}$ For alternative viewpoints, see Meltzer, et al (1999) and Keefe, et al (1999).

${ }^{5}$ Related studies have examined the productivity of drugs used to treat depression (Berndt, et al 2002), the benefits of newer prescription drugs (Lichtenberg, 1996 and 2001), and the benefits of new technologies or more intensive use of existing ones (e.g. McClellan, et al (1994), Cutler, et al (1998), Wennberg and Cooper (1999), and Cutler and McClellan (2001)).
} 
schizophrenia patients in 1994 with their observably similar counterparts from 2000. This strategy essentially investigates whether the shift to Risperdal, Zyprexa, and Seroquel has reduced the rate of hospitalization, the time spent in the hospital during the acute event, or the time hospitalized in future periods. Despite a sharp increase in anti-psychotic drug spending between 1994 and 2000, the pre-post trajectory of health care utilization for hospitalized schizophrenia patients is quite similar during these two time periods, suggesting that the drugs have not reduced the incidence or severity of hospitalizations nor increased the speed with which Medicaid recipients recover.

In addition to focusing on only those schizophrenia patients hospitalized during these two time periods, I next examine the entire distribution of Medicaid spending and health outcomes for schizophrenia patients in 1994 and 2001. My findings here demonstrate that a substantial increase in spending on anti-psychotic drugs in all ten deciles of the distribution can explain more than half of the $41 \%$ increase in Medicaid spending on this group. Additionally, there is virtually no change in the overall hospitalization rate and the incidence of adverse side effects increases in all ten deciles of the expenditure distribution, providing further evidence that the drugs have not led to significant improvements in the health of Medicaid recipients.

There are at least two potential limitations of this cohort-based approach. First, the characteristics of individuals diagnosed with schizophrenia may be changing over time. Second, there are no doubt other shifts in medical care technology and in treatment patterns occurring over this time period. For both of these reasons, differences in means and/or distributions between 1994 and 2001 will not be solely driven by the shift to atypical anti-psychotic drugs.

Thus in my third estimation strategy, I investigate the impact of atypical anti-psychotic drugs by comparing Medicaid-eligible schizophrenia patients who take the drug with observably similar individuals in the same time period who do not take the drug. To do this, I use the patient's psychiatrist as an instrumental variable for the probability of taking the drug. Certain psychiatrists are significantly more likely - conditional on their patients' observable characteristics - to prescribe atypical anti-psychotic drugs to their schizophrenia patients. To obtain a sufficient number of patients for each psychiatrist, I use a $25 \%$ sample rather than a $5 \%$ sample for this third strategy. And my empirical results here - though not as precisely estimated as the previous two - are broadly consistent with the earlier results, though I am unable to rule 
out the possibility that unobservable health is driving the difference across psychiatrists rather that pharmaceutical advertising or some other plausibly exogenous factor.

While none of the strategies used in this paper is free from potential problems, the fact that all three point in the same direction is reassuring. Taken together, my results suggest that the $670 \%$ increase in government spending for anti-psychotic drugs during the 1993-2001 period has not significantly improved the health of Medicaid recipients with psychotic illness, though it is worth emphasizing that my measures of health are not as complete as the corresponding ones for health care spending. Given that so few of the consumers of atypical anti-psychotic drugs share in its price, it may not be surprising that the benefits of these treatments appear to be much smaller than their costs to taxpayers. But this issue is likely to become more important in the years ahead as the fraction of prescription drugs specifically and medical care generally paid for by the government through Medicaid, Medicare, and other programs continues to increase.

The outline of the paper is as follows. Section two presents an illustrative model that examines the effect of Medicaid on the efficiency of prescription drug spending. Section three describes the growth in the disability rolls that has been partly responsible for the increase in Medicaid prescription drug spending, and then summarizes trends in spending on prescription drugs and on anti-psychotic drugs specifically. In section four I describe the data used in this study, which includes complete claims data for a 5\% sample of Medicaid recipients from the state of California for the 1993-2001 period. In section five I use individual fixed effects specifications to investigate the effect of Risperdal, Zyprexa, and Seroquel on both Medicaid spending and on health outcomes. Section six presents two alternative estimation strategies for estimating these effects and section seven concludes.

\section{Modeling the Effect of Medicaid on the Efficiency of Prescription Drug Spending}

For those Medicaid recipients not enrolled in a managed care plan, the government directly reimburses hospitals, pharmacies, and other health care providers for any services that are received by the recipient. The government must therefore choose prices for every covered service and often relies on the prices that exist in the private sector. While this may help the government to choose reimbursement rates for specialized treatments that are difficult to evaluate, it may have a significant impact on equilibrium prices in the private market. This effect will be especially large for drugs consumed differentially by Medicaid recipients. 
Consider, for example, a pharmaceutical firm's optimization problem after acquiring FDA approval for drug j. Assume for simplicity that the firm has a patent for the drug, that there is just one period, that there is a constant marginal cost equal to $\mathrm{c}$, and that demand for the drug does not influence the demand for other products produced by this same firm. In the absence of Medicaid, the firm will simply choose the price of the drug to satisfy the following equation:

$$
\text { (1) } \frac{P_{j}^{*}-c}{P_{j}^{*}}=\frac{1}{\varepsilon_{j}}
$$

with $\varepsilon_{j}$ equal to the demand elasticity at the optimal price. Thus the more elastic is the demand for the drug the lower will be its equilibrium price.

Now assume that a fraction $\alpha$ of potential customers are eligible for the Medicaid program. ${ }^{6}$ If the demand function for this group is simply $\alpha$ times the total market demand, then the optimal price will increase to satisfy the following equation:

$$
\text { (2) } \frac{P_{j}^{*}-c}{P_{j}^{*}}=\frac{1}{\varepsilon_{j}} *\left(1+\theta^{*}\left(\frac{\alpha Q_{j}(0)}{(1-\alpha) Q_{j}^{*}}\right)\right)
$$

with $\theta$ equal to the fraction of the price that the government pays the pharmaceutical company, $\alpha Q_{j}(0)$ the number of units of the drug consumed by Medicaid recipients, and $(1-\alpha) Q_{j}^{*}$ equal to the number of units consumed by unsubsidized consumers at the price $P_{j}^{*}$. The optimal price will therefore be an increasing function of the ratio of Medicaid prescriptions to privately insured purchases and of the reimbursement rate $\theta$ (which is assumed to be greater than $\frac{c}{P_{j}^{*}}$ ). Intuitively, as the fraction of subsidized customers increases, the effective demand elasticity declines, thus leading to an increase in the firm's profit-maximizing price. In the case of a simple linear demand curve $Q_{j}=N-\mu P_{j}$ this optimal price will equal:

\footnotetext{
${ }^{6}$ The typical state government pays $90 \%$ of the average wholesale price to the pharmaceutical firm for each prescription and then receives a rebate that is typically equal to $15 \%$ of the average manufacturer's price. See Scott-Morton (1998) for an examination of the effect of Medicaid rebates on pharmaceutical pricing. Average wholesale price (AWP) is the drug's list price, whereas the average manufacturer's price (AMP) is approximately equal to total revenues divided by total prescriptions. Because AWP is greater than AMP, the price paid by Medicaid is often close to the average private price, with this difference varying across drugs.
} 


$$
\text { (3) } P_{j}^{*}=\frac{N}{2 \mu}+\frac{c}{2}+\frac{\alpha \theta N}{2 \mu(1-\alpha)}
$$

and thus some privately paying customers who would purchase the drug in the absence of a Medicaid program will no longer purchase if $\alpha>0$. As the Medicaid market share increases, the fraction of non-Medicaid patients that purchase the drug declines. ${ }^{7}$ Because some low valuation Medicaid consumers end up purchasing the drug while relatively high valuation private customers do not, the program reduces allocative efficiency in this market.

In addition to increasing the prices of prescription drugs above those that would prevail in the absence of this government intervention, the Medicaid program will lead to inefficient treatment decisions by Medicaid recipients. Consider, for example, the decision for an unsubsidized individual $\mathrm{j}$ with an illness that has $\mathrm{K}$ possible drug treatments. For simplicity assume that the person is alive for just one period and that he/she maximizes the utility function $U j=\alpha_{j} H_{j}+\left(1-\alpha_{j}\right) C_{j}$, with $\mathrm{H}_{\mathrm{j}}$ and $\mathrm{C}_{\mathrm{j}}$ equal to health and consumption, respectively. One can model the effect of the drugs on the individual's health as follows:

$$
\text { (4) } \Delta H_{j}=\beta_{1 j} D_{1 j}+\beta_{2 j} D_{2 j}+\ldots+\beta_{K j} D_{K j}
$$

with the indicator variable $D_{\mathrm{kj}}$ equal to one if the person takes drug $\mathrm{k}$ and zero otherwise, and $\beta_{\mathrm{kj}}$ equal to the effect of the drug on health, which may vary across individuals. By taking the drug, the person may reduce the need for other types of health care (e.g. physician visits, hospital stays, etc.) and thus the resulting change in consumption may differ from the cost of the drug. This change can be written as:

$$
\text { (5) } \Delta C_{j}=\mu_{1 j} D_{1 j}+\mu_{2 j} D_{2 j}+\ldots+\mu_{K j} D_{K j}
$$

with $\mu_{\mathrm{kj}}$ equal to the change in consumption that results if individual takes drug $\mathrm{k}$. If person $\mathrm{j}$ knows the parameters $\beta_{\mathrm{kj}}$ and $\mu_{\mathrm{kj}}$, then he/she will maximize utility by choosing the drug $\mathrm{k}$ (if any) that maximizes $\alpha_{j} \beta_{k j}-\left(1-\alpha_{j}\right) \mu_{k j}$, which is equal to the change in utility that results when an individual takes the drug. ${ }^{8}$ Individuals with similar illnesses will make different choices both because of heterogeneous treatment effects and also because of variation across individuals in

\footnotetext{
${ }^{7}$ This could plausibly lead some private customers to try to qualify for Medicaid, thus introducing a feedback effect that leads to further increases in the price.

${ }^{8}$ In practice individuals and their physicians are likely to be uncertain about $\beta_{\mathrm{kj}}$ and $\mu_{\mathrm{kj}}$. Thus after taking the drug they face a signal extraction problem - how much of the change in health from one period to the next is due to the drug versus some other factor.
} 
the weight placed on health versus consumption. Some would choose the most expensive drug, but only if its health benefits were sufficiently large to justify the resulting loss in utility from reduced consumption.

The treatment decision would often be different if the individual did not share in the cost of the drug because of full insurance from the Medicaid program. In this case, he/she would simply choose the drug that yields the biggest increment to health $\beta_{\mathrm{kj}}$, thus potentially choosing a drug with a benefit substantially lower than its cost to taxpayers. Adding uncertainty to the costs and benefits of the drugs or taking account of agency issues that result when a person relies on physician advice does not change the main insight - purchase decisions may be quite inefficient when the co-pay is set to zero.

Thus for at least two reasons, Medicaid spending on the more than 20,000 prescription drugs currently covered by the program may not generate health benefits or reductions in other health care utilization that justify the additional spending. First, the program's reimbursement rules will increase pharmaceutical prices above those that would prevail in the absence of Medicaid, with this effect likely to be especially important for drugs consumed differentially by beneficiaries of this program. Second, because Medicaid recipients do not share in the cost of their prescription drugs, they will choose some with a benefit substantially lower than the cost to taxpayers. $^{9}$

In the empirical work that follows, I investigate the effect of a new category of prescription drugs purchased differentially by Medicaid recipients on both government spending and health outcomes for a sample of individuals insured by this program. While I unfortunately cannot measure the dollar value that each Medicaid recipient places on the drugs that he/she takes, I can examine whether the sharp increase in spending for these drugs has on average yielded similarly significant improvements in observable measures of health or reductions in the utilization of other health care services.

\section{Medicaid and the Market for Anti-Psychotic Drugs}

\section{A. The Rise in the Disability Rolls and the Increase in Medicaid Enrollment}

From 1989 to 2001, the number of non-elderly individuals receiving disability benefits from the federal government's Supplemental Security Income (SSI program) more than doubled,

\footnotetext{
${ }^{9}$ One additional reason is that providers may have financial or other incentives to prescribe certain drugs.
} 
increasing from 2.28 million to 4.69 million, with most of the increase occurring during the first four years of this twelve-year period. To qualify for SSI disability benefits, a person must have a medically determinable impairment that prevents him or her from engaging in "substantial gainful activity" (SSA, 2002). Additionally, the person's income and assets must be quite low because the program is means tested. An additional 2.00 million elderly individuals are currently eligible for SSI and all 6.69 million SSI recipients obtain health insurance through the Medicaid program. Total cash payments to this group in 2001 amounted to more than $\$ 34$ billion. Despite the fact that only one out of every six Medicaid recipients are on SSI, those eligible for SSI benefits accounted for approximately $65 \%$ of the $\$ 221$ billion in Medicaid expenditures during the 2001 fiscal year. Thus health care payments on behalf of this group were more than four times as large as the $\$ 34$ billion in cash transfers to them. ${ }^{10}$

The growth in SSI receipt since the 1980s has not been uniform across diagnosis groups. The most striking change has been the increase in the fraction of program participants who qualified because of a mental disorder. This number has increased by more than $135 \%$ since 1989, from 1.20 million to 2.82 million. The growth in eligibility among all other diagnosis groups, while still a substantial $73 \%$ (from 1.09 million to 1.88 million), has been much less marked. It therefore seems plausible that the impact of the Medicaid program on the market for drugs used to treat mental disorders has increased over this time period.

B. Trends in Medicaid Prescription Drug Spending in the U.S.

From 1996 to 2001, real Medicaid spending on prescription drugs approximately doubled from $\$ 12.5$ billion to $\$ 24.7$ billion. $^{11}$ Growth in this service category far outpaced all other Medicaid spending, which increased by just $20 \%$ from $\$ 164.0$ billion to $\$ 196.5$ billion during this same time period. Recent research suggests that the growth in pharmaceutical spending may actually have lowered medical care outlays below what they otherwise would have been, as new

\footnotetext{
${ }^{10}$ Many SSI recipients are also eligible for disability or retiree benefits from social security. These 2.39 million "dually eligible" individuals are therefore receiving cash transfers from SSI and OASDI, and obtain health insurance from both Medicaid and Medicare. See Autor and Duggan (2003) for an examination of the factors leading to growth in the disability rolls.

${ }^{11}$ Net spending on prescription drugs in these two years amounted to $\$ 10.3$ and $\$ 19.7$ billion, respectively, as pharmaceutical firms paid rebates to state governments equal to approximately $20 \%$ of gross Medicaid revenues in each year.
} 
prescription drugs may improve health and thus lower other spending for other types of health care utilization (Lichtenberg, 1996 and 2001). ${ }^{12}$

The Food and Drug Administration classifies each drug that it approves into one of twenty major classes. Table 1 provides information on Medicaid spending for each of these classes in 1996 and 2001. In both years, spending for drugs used to treat Central Nervous System (CNS) disorders was greater than for any other therapeutic category. CNS drugs include those used to combat most types of mental disorders, including anti-depressants, anti-psychotics, and anti-anxiety medications. Not surprisingly given the growth in the SSI rolls described above, the increase in spending in this therapeutic category has been more rapid than for all other prescription drugs. In 1996, the Medicaid program disbursed \$1.99 billion for CNS drugs and this number more than tripled to $\$ 6.00$ billion by 2001 .

Within the CNS class of drugs, there are several minor classes. The two largest with respect to Medicaid spending are anti-depressants and anti-psychotics. This first group includes drugs used to treat various forms of depression, while drugs used to treat schizophrenia, dementia, and other psychotic illnesses are in the latter group. As Table 2A shows, these two categories account for more than $80 \%$ of the $\$ 6$ billion in Medicaid spending on CNS drugs. From 1996 to 2001, real Medicaid expenditures on drugs used to treat psychotic illness and depression increased by $266 \%$ and $145 \%$, respectively. Interestingly, while the increase in the latter category was driven primarily by a rise in the number of prescriptions, the surge in spending for drugs used to treat schizophrenia is mainly explained by a $148 \%$ increase in the average price for a prescription.

Although the number of anti-depressant prescriptions filled for Medicaid recipients exceeded the corresponding number of anti-psychotic prescriptions, Table 2B demonstrates that the Medicaid market share is substantially greater for this latter category. In this table, I list the top three selling (by expenditures) drugs for each of the two drug classes in 2001. Among antidepressants, Medicaid accounts for roughly 17 percent of all prescriptions, whereas beneficiaries of this program received approximately 75 percent of those filled to treat psychotic illnesses. This difference corresponds to a significant difference in the parameter $\alpha$ from the theoretical section above. Consistent with the model's main prediction, the drug class with a greater level of

${ }^{12}$ This study estimates the productivity of pharmaceutical spending generally, but does not investigate the efficiency of Medicaid spending on prescription drugs nor on anti-psychotic drugs 
(and presumably a greater increase in) the Medicaid market share during recent years has been characterized by a much sharper increase in average prices.

\section{The Shift to Atypical Anti-Psychotics}

Anti-psychotic drugs are used primarily for the treatment of schizophrenia. The FDA's approval of Clozaril in 1989 marked the start of a significant change in the treatment of this illness. Prior to this approval, schizophrenia patients were typically treated with conventional anti-psychotics known as neuroleptics. These drugs helped individuals to deal with delusions, hallucinations, and other positive symptoms of this illness, but had a number of adverse side effects including muscle spasms, tremors, and an increased risk of tardive dyskinesia. Clozaril was the first in a line of atypical anti-psychotics that appeared to lower the incidence of these extrapyramidal side effects while also treating both the positive and the negative symptoms (e.g. withdrawal, lack of motivation, blunted emotions) of schizophrenia (Lamberg, 1998). During the subsequent decade, the FDA approved several new atypical anti-psychotics, including Risperdal in 1993, Zyprexa in 1996, and Seroquel in 1997, which were considered to have even fewer side effects than Clozaril. These four drugs now account for $73 \%$ of all anti-psychotic prescriptions filled in the U.S. and more than $91 \%$ of total spending on anti-psychotic drugs (NIHCM, 2002).

Table 2C demonstrates that the shift to Risperdal, Zyprexa, and Seroquel that occurred from 1996 to 2001 is the main reason for the sharp increase in Medicaid prescription drug spending and in average prices during this time period. These three atypical anti-psychotic drugs entered the market in January of 1994 (Risperdal), October of 1996 (Zyprexa), and October of 1997 (Seroquel). The table also shows that the market share of Clozaril, the top-selling brand drug during the 1990-1996 period, fell sharply from 1996 to $2001 .^{13}$ Additionally, the fraction of prescriptions that were for generic drugs fell from $48 \%$ to $28 \%$.

For each one of these three drugs, there are multiple dosage amounts and/or route types. Table 2D shows that there are currently ten separate versions of Zyprexa that are covered by the Medicaid program. Medicaid payments for Zyprexa are greater than for any other drug, with

\footnotetext{
specifically.

${ }^{13}$ The decline in Clozaril's market share was likely driven by studies suggesting that it led to an increase in the incidence of agranulocytosis in patients.
} 
Risperdal and Seroquel at numbers two and eight, respectively. ${ }^{14}$ This is quite striking given that just $1 \%$ of Medicaid recipients have been diagnosed with schizophrenia, and reflects the fact that atypical anti-psychotics are substantially more expensive than the average prescription drug.

While dozens of studies have investigated whether these new drug treatments lead to improvements in mental functioning (Meltzer, et al, 1999; Lamberg, 1998; Keefe, et al, 1999) or to changes in the incidence of certain side effects (Gianfrancesco, et al, 2002; Leucht, et al, 1999; Sernyak, et al, 2002), no study has examined the effect of the new drugs on both health outcomes and on health care costs. One needs both when estimating the productivity of this important category of prescription drugs that is purchased almost exclusively by the government for beneficiaries of Medicaid and other government programs.

\section{The Medicaid Sample and the Diffusion of Atypical Anti-Psychotic Drugs}

To estimate the change in productivity for the largest category of Medicaid prescription drug spending, I use an administrative data set constructed by the California Department of Health Services (DHS) that contains all Medicaid claims for a sample of California residents with at least one month of Medicaid eligibility from January of 1993 to December of 2001. ${ }^{15}$ The claims data include all Medicaid payments made to hospitals, nursing homes, pharmacies, physicians, and other health care providers for $5 \%$ of California's Medicaid recipients. There are 729,562 individuals in the sample with at least one month of Medicaid eligibility, implying that approximately 14.6 million Californians (more than $40 \%$ of the state's residents) were eligible for the program in one or more months during this nine year time period.

Except those for prescription drugs, every Medicaid claim in the data has a primary diagnosis code that identifies the main reason for the health care treatment. During the nine-year sample period, there are 9646 individuals with one or more claims that have a primary diagnosis of schizophrenia, ${ }^{16}$ implying that just $1.3 \%$ of individuals eligible for Medicaid were at some point diagnosed with schizophrenia. For the empirical work that follows below, I pulled all

\footnotetext{
${ }^{14}$ Ranking drugs by total revenues in the U.S., Zyprexa and Risperdal are at numbers 12 and 20, respectively. Among the top thirty drugs, Zyprexa has the highest price per prescription and Risperdal is the third most expensive.

${ }^{15}$ See Duggan (2002) for a more detailed description of this data. There are clear disadvantages to focusing on just one state. Unfortunately, because each state administers its own Medicaid program and uses its own method for coding claims, it is not currently possible to assemble an individual-level data set for a representative sample of Medicaid recipients in the U.S.

${ }^{16}$ A claim is coded as a schizophrenia claim if the first three digits of the diagnosis code are 295.
} 
Medicaid claims and eligibility information for these 9646 individuals. I then drop all data for the 302 individuals without a valid social security number (encrypted in my data) or with data discrepancies across years (e.g. listed as born in 1926 in one year and in 1934 in another year). Finally, I drop the 1240 individuals with one or more months of Medicaid eligibility in one of the seven counties with a county organized health system (COHS) because the claims data will be missing for most Medicaid recipients in these places. The final sample contains all Medicaid claims and eligibility information for 8104 individuals diagnosed with schizophrenia at some point between January of 1993 and December of 2001 while eligible for Medicaid.

Every Medicaid prescription drug claim has an eleven digit National Drug Code (NDC) that allows me to uniquely identify the drug that was prescribed. There are currently more than 30,000 active NDCs, and this number changes from one period to the next as new drugs are introduced, new dosage amounts and/or route types are approved for existing drugs, and old drugs are discontinued. Using the NDC variable, I merge the Medicaid prescription drug claims with files constructed by the Food and Drug Administration that have several variables including the drug's name, active ingredient, dosage, and drug class. ${ }^{17}$

Table 3A lists spending on anti-psychotic drugs for the schizophrenia sample and for all Medicaid recipients in the 5\% sample. The 8104 individuals diagnosed with schizophrenia account for more than $60 \%$ of the $\$ 21$ million spent on anti-psychotic drugs in the 5\% sample, with most of the remaining spending for individuals diagnosed with bipolar disorder or dementia but never with schizophrenia. As the table shows, the average price for an anti-psychotic prescription increased by a factor of five from 1993 to 2001, and total spending on anti-psychotic drugs increased by $670 \%$ during this period. By 2001, Risperdal, Zyprexa, and Seroquel accounted for nearly $58 \%$ of all anti-psychotic prescriptions and for more than $85 \%$ of spending. Table 3B demonstrates that these three drugs approved by the FDA during the mid-1990s are significantly more expensive than the average anti-psychotic drug in 1993. For example, at $\$ 391$ per prescription, Zyprexa is ten times more expensive than the average anti-psychotic prescription was in 1993.

Table 4 provides summary statistics for the individuals in the schizophrenia sample, with snapshots in the first quarter of 1993, 1997, and 2001. The first three columns include information for individuals eligible for Medicaid who have a schizophrenia claim at any point

\footnotetext{
${ }^{17}$ The most current set of these files can be found at http://www.fda.gov/cder/ndc/.
} 
between January of 1993 and December of 2001. The number of recipients differs across the three time periods because of both entry and exit (either death or becoming ineligible for Medicaid) and Appendix Table 1 lists this information for the 36 quarters from early 1993 to late $2001 .^{18}$ The last three columns include summary statistics for individuals with one or more schizophrenia claims in the first quarter of 1993, 1997, and 2001. In addition to demographic information, the table provides average Medicaid spending, rates of health care utilization, and information on the fraction of the sample with side effects that previous studies suggest may be affected (either positively or negatively) by Risperdal, Zyprexa, and Seroquel.

From 1993 to 2001, the number of Medicaid recipients diagnosed with schizophrenia one or more times during the first three months of the year rose by just 7.2\%, from 2329 to 2496 . This suggests that neither growth in the SSI rolls after 1993 nor a change in the definition of this mental illness led to a significant change in the average characteristics of individuals in the sample. The summary statistics reveal that there is a substantial shift in the age distribution of Medicaid recipients with schizophrenia, with the fraction between 45 and 64 years old increasing from $31 \%$ in 1993 to nearly $44 \%$ by 2001 . This increase is not surprising given the aging of the population, though it is worth bearing in mind when examining any trends in the distribution of spending, utilization, or health during the nine-year period studied here.

From 1993 to 2001, the fraction of individuals diagnosed with schizophrenia taking Risperdal, Zyprexa, or Seroquel increased from 0 to more than $60 \%$, with a resulting increase in quarterly spending on anti-psychotic drugs of $\$ 153$ to $\$ 809$. This rise coincided with a sharp increase in spending on other types of prescription drugs (from $\$ 172$ to $\$ 402$ ) and on all other Medicaid services (from \$2313 to \$2612). The fraction admitted to a hospital or long-term care facility remains fairly constant, increasing slightly from $19.7 \%$ to $20.6 \%$, while there is a similarly small increase in the fraction with extrapyramidal symptoms (EPS). ${ }^{19}$ Strikingly, there is a significant increase in the fraction diagnosed with diabetes $(73 \%)$ and with abnormal weight

18 Just $42 \%$ of the 8104 individuals in the schizophrenia sample are eligible for Medicaid in all 36 quarters from early 1993 to late 2001, and thus the panel data set employed in the subsequent empirical work is unbalanced. This occurs because 2235 of the individuals in the sample die or are no longer eligible for Medicaid by December of 2001 and because 2451 of those in the sample have their first month of eligibility after the first quarter of 1993.

${ }^{19}$ A person is coded as having EPS if they have any Medicaid claims with a primary diagnosis ICD-9 code that begins with 332 (Parkinson's disease) or 333 (other extrapyrmidal disease and abnormal movement disorders). See Leucht, et al (1999) for a literature review. 
gain $(118 \%),{ }^{20}$ and the fraction diagnosed with one or more of the five side effects most commonly associated with anti-psychotic drugs rises from $6.8 \%$ to $10.3 \%$.

Thus while it is certainly true that the characteristics of those in the sample are changing over this period, a preliminary examination of the trends in spending, utilization, and health suggest that atypical anti-psychotic drugs have not dramatically lowered other Medicaid spending nor improved health. It is worth emphasizing, however, that the health outcomes measured here using the Medicaid claims data may not fully capture all of the effects of atypical anti-psychotics on individual health and well being. ${ }^{21}$

The following sections use three identification strategies to estimate the effect of one of the most rapidly growing categories of Medicaid prescription drug spending on both health care spending and on health outcomes.

\section{The Impact of Atypical Anti-Psychotics on Medicaid Spending and Health Outcomes}

The first step in estimating the effect of any health care treatment is to determine the set of individuals who are potential candidates for it. The three drugs described above were approved by the FDA during the mid-1990s for the treatment of schizophrenia but are now also used to treat individuals with bipolar disorder, dementia, and other psychotic illnesses. ${ }^{22}$ In the empirical work that follows, I focus on individuals diagnosed with schizophrenia because this group accounts for the majority of atypical anti-psychotic prescriptions in the Medicaid sample

${ }^{20}$ The first of these two includes ICD-9 codes that begin with 7831 (abnormal weight gain) and 2720-2724 (hypercholesterolemia, hyperlipidemia, and related illnesses), while diabetes includes ICD-9 codes beginning with 250 or 6480 . See Zimmerman (2003) for a literature review regarding the effect of atypical anti-psychotics on abnormal weight gain and related illnesses. Gianfrancesco, et al (2002) investigate the effect of atypical anti-psychotics on the incidence of type 2 diabetes.

${ }^{21}$ For example, Meltzer (1999) argues that atypical anti-psychotics are superior to conventional anti-psychotic drugs with respect to improvements in cognitive functioning. This view is controversial, however, with others arguing that the available evidence suffers from serious methodological limitations, including non-random assignment to the treatment group, small sample sizes, pre versus post designs with no control group, and few findings that have been replicated (Carpenter and Gold, 2002) . In fact, some researchers have shown that conventional drugs produce a similar effect to atypicals when the former are used in lower dosage amounts (Green, 2002).

${ }^{22}$ In the year following their FDA approvals, approximately $90 \%$ of Risperdal, Zyprexa, and Seroquel prescriptions were written for individuals diagnosed with schizophrenia. By 2001, this fraction had declined to 52\% for Risperdal, 62\% for Zyprexa, and 61\% for Seroquel, with the remaining prescriptions filled primarily for those with bipolar disorder or dementia. 
and because it gives me a more homogeneous sample with which to evaluate the impact of the new drugs.

Table 5A provides information on the fraction of individuals in the sample who took Risperdal, Zyprexa, and Seroquel in each quarter from early 1994 to late 2001. These three drugs first entered the market in January of 1994, October of 1996, and October of 1997, respectively. In all three cases, just a small fraction of the sample took the drug in the year following its FDA approval but this share consistently increased in subsequent periods. By the end of 2001, approximately $38 \%$ of the sample had filled at least one Risperdal prescription, with the corresponding shares for Zyprexa and Seroquel equal to 39\% and 14\%, respectively. Most of the individuals who took one of these drugs also had one or more prescriptions for the other two (Table 5B). For example, of the 3060 individuals with at least one Risperdal prescription, more than $62 \%$ also took either Zyprexa or Seroquel during the time period of interest.

\section{A. Challenges in Identifying the Effect of Drug Treatments}

To estimate the effect of drug D on outcome variable $\mathrm{Y}$ for this sample of Medicaid recipients, one could estimate the following cross-sectional equation:

$$
\text { (6) } Y_{j}=\alpha+\beta_{j} D_{j}+\gamma X_{j}+\varepsilon_{j}
$$

with $D_{j}$ equal to one if individual $j$ took the drug and zero otherwise, $X_{j}$ equal to a set of observable characteristics, and $\beta$ representing the causal effect of the drug on $Y_{j}$. This parameter could vary across individuals and thus I index it by $\mathrm{j}$. The problem with estimating this equation is well known - the individuals who take the drug may differ in unobservable ways from those who do not. Thus a cross-sectional regression like the one above would lead to a biased estimate if this unobserved factor is correlated with the treatment variable D. One strategy for dealing with this problem of omitted variables is to use panel data. If one assumes that the unobserved factor does not vary over time then one can difference it out using individual fixed effects. This assumption is unlikely to hold, however, as changes in treatment are likely to be at least partially driven by changes in outcome variables (e.g. health).

To lower the likelihood that any changes in treatment are caused by unobserved changes in health, I focus on individuals who were diagnosed with schizophrenia before each drug was approved, and compare outcomes for individuals shifted to the new drugs with their counterparts who were not. I also exploit variation in the timing of the shift, as some schizophrenia patients started to take a drug in the first quarter that it was marketed while others first took it much later. 
By defining the sample in this way, I can calculate a baseline level of spending for individuals already diagnosed with schizophrenia when the treatment of interest was not yet available. It will of course still be possible that a change in the severity of an individual's schizophrenia coincided with the FDA approval date, and I will test for this below by estimating pre-existing trends in the outcome variables of interest. It is plausible that this is less likely as the time of an individual's first prescription for a drug gets closer to its FDA approval date, and I therefore contrast my estimated effects for early and late adopters of these three new health care treatments.

In addition to the date of the first prescription, the number of prescriptions filled for each drug varies substantially across individuals who consume it. For example, as shown in Table 6, more than $24 \%$ of the Medicaid recipients diagnosed with schizophrenia in 1993 who subsequently take Risperdal have three or fewer prescriptions from 1994 to 2001 . This is approximately equal to the fraction with 35 or more Risperdal prescriptions in that same eightyear period. This heterogeneity in treatment intensity makes the evaluation problem still more difficult, as average outcomes for individuals who stop taking the drug are likely to differ from the effect for individuals who continue to take it.

\section{B. The Impact of Atypical Anti-Psychotic Drugs: Evidence from Fixed Effects Specifications}

I begin by examining the effect of Zyprexa - the drug with the highest Medicaid expenditures in the U.S. - on both health care spending and health outcomes. For this analysis, I restrict attention to the 3363 individuals who were diagnosed with schizophrenia at least once in the year just before the approval of this drug. I define an indicator variable $Z_{\mathrm{jt}}$ that is equal to one in the first quarter that individual $\mathrm{j}$ takes Zyprexa and in every subsequent quarter that he/she remains in the sample and is equal to zero otherwise. Thus even if person $\mathrm{j}$ fills a prescription for Zyprexa in period $\tau$ but does not take this drug in any future quarter, the variable $Z_{\mathrm{jt}}$ remains equal to 1 for all $t>\tau$. I then estimate specifications of the following type:

$$
\text { (7) } Y_{j t}=\beta X_{j t}+\gamma Z_{j t}+\mu_{j}+\lambda_{t}+\varepsilon_{j t}
$$

In this equation, $Y_{j t}$ is equal to the outcome variable of interest, $X_{j t}$ a set of time-varying individual characteristics, $Z_{\mathrm{jt}}$ the Zyprexa indicator, and $\mu$ and $\lambda$ a vector of individual and year*quarter fixed effects, respectively. To the extent that unobserved differences across individuals do not vary over time, they will be picked up by the inclusion of the person fixed effects $\mu_{\mathrm{j}}$. Common changes in the outcome variable from one period to the next will be 
captured by the time effects $\lambda_{\mathrm{t}}$. The main parameter of interest is $\gamma$, the average change in the outcome variable $Y_{\mathrm{jt}}$ following individual j's first Zyprexa prescription.

For at least two reasons, the coefficient estimate for $\gamma$ is unlikely to represent the average effect of taking the drug for those who ever take it. First, it is plausible that a change in health is sometimes responsible for an individual's first Zyprexa prescription. This would be represented by a correlation between the error term $\varepsilon_{\mathrm{jt}}$ and the treatment variable $Z_{\mathrm{jt}}$ in (7), and would lead to a biased estimate of the effect of the drug on those who take it. If, for example, psychiatrists tend to prescribe the drug when an individual's health is deteriorating, then the estimate for $\gamma$ from (7) would be biased downwards, suggesting that the health benefit of the drug is smaller than it actually is. ${ }^{23}$

Second, there is substantial heterogeneity across individuals in treatment intensity. ${ }^{24}$ Some who take the drug in late 1996 are still taking it five years later, whereas others stop taking the drug after their first prescription. Thus even if the unobserved $\varepsilon_{\mathrm{jt}}$ is uncorrelated with the treatment variable $Z_{\mathrm{jt}}$, an OLS estimate for $\gamma$ will be disproportionately affected by those who take the drug for relatively many periods. Rather than capturing the average effect for those ever treated with the drug, the coefficient estimate would instead represent a weighted average of the individual $\gamma_{j}$ values, with the weight depending on the number of quarters in which each recipient took the drug. If the Medicaid recipients who take the drug for many periods are the ones who derive the greatest benefit, ${ }^{25}$ then an estimate for $\gamma$ will be biased upwards, suggesting for example that the average health benefit is greater than it would have been if all recipients had continued with the treatment. It is therefore more appropriate to think of the coefficient estimate for $\gamma$ from a specification similar to (7) as capturing the average change in the outcome variable after taking Zyprexa for the first time rather than an average causal effect.

${ }^{23}$ The "true" effect of the drug for individual $\mathrm{j}$ in period $\mathrm{t}$ is equal to $\mathrm{Y}_{\mathrm{jt}}\left(\mathrm{Z}_{\mathrm{jt}}=1\right)-\mathrm{Y}_{\mathrm{jt}}\left(\mathrm{Z}_{\mathrm{jt}}=0\right)$, but this difference in potential outcomes is not what estimation of (7) captures if a change in $\varepsilon_{\mathrm{jt}}$ is influencing the treatment decision.

${ }^{24}$ A related issue is the variation in dosage amount across individuals. The most common dosage amounts are 10 and 5 milligrams (per pill).

${ }^{25}$ When estimating the benefit of Zyprexa after taking it for the first time, individuals and their healthcare providers essentially face a signal extraction problem. A change in health from period $\mathrm{t}$ to $\mathrm{t}+1$ could be driven by the change in treatment or by a change in $\varepsilon_{\mathrm{jt}}$. Individual $\mathrm{j}$ may adopt a decision rule - only if $\Delta \mathrm{Y}_{\mathrm{jt}}$ is above some threshold would they continue to take it, and this 
Table 7A provides results from specifications similar to (7) above with several different outcome variables. In these regressions, the unit of observation is a person-quarter, with $\mathrm{Y}_{\mathrm{jt}}$ equal to the value of outcome variable $\mathrm{Y}$ for person $\mathrm{j}$ in January through March, April through June, July through September, or October through December of a particular year. I use a shorter time period than a year to more accurately capture when a person's health care treatment changes. The time period studied extends from October of 1995 to December of 2001 - thus the maximum number of observations for anyone in this regression is 25 . I include the 3363 individuals diagnosed with schizophrenia at some point between October of 1995 and September of 1996 before the launch of Zyprexa in October of $1996 .{ }^{26}$

The dependent variable for the specifications summarized in the first two columns is an indicator variable that equals one if the person has one or more Zyprexa prescriptions in the quarter and zero otherwise. In these regressions and the subsequent ones I control for the number of months that a person is eligible for Medicaid in the quarter and the fraction of those months insured by Medicare, ${ }^{27}$ eligible for SSI disability benefits, and in a managed care plan. The statistically significant coefficient estimate of 0.661 for the indicator variable in the first column implies that Medicaid recipients who take Zyprexa for the first time in period $\tau$ have one or more Zyprexa prescriptions in approximately $66 \%$ of all future periods (including $\tau$ ). Given that a large fraction of individuals stop taking this drug after just a few prescriptions, the fact that this estimate is less than 1.00 is not surprising. Combined with the coefficient estimate of 1.850 for the number of prescriptions specification in column (3), this first set of results imply that the average number of Zyprexa prescriptions in a quarter for Medicaid recipients with at least one is 2.80. This makes sense given that the typical prescription provides a one-month supply. The

decision rule is likely to vary across individuals and their healthcare providers. Complicating things further, the effect of the drug for individual $\mathrm{j}$ is likely to vary from one period to the next. ${ }^{26}$ I begin with October of 1995 because it provides at least four quarters of pre-Zyprexa spending and utilization information for all individuals in the sample. The results are quite similar if I include all 36 quarters in these regressions. Of the 3363 individuals included in these regressions, 2286 (68\%) are observed in all 25 quarters.

${ }^{27}$ Medicaid covers just part of the health care expenses for those dually eligible for Medicare. Medicare covers most of the costs of hospital stays and physician visits, with Medicaid paying any co-pays or deductibles for these services and covering virtually all of the prescription drug and nursing home expenses. Thus my spending data does not capture total government spending on medical care for these dual eligibles. The results summarized below are qualitatively similar if I exclude those ever eligible for Medicare or focus exclusively on this group. 
coefficient estimate of $\$ 663$ for the Zyprexa spending specification summarized in column (5) implies that the average cost of a Zyprexa prescription for individuals in this sample is $\$ 358$.

If spending on Zyprexa led to a reduction in other health care spending and changes in health (either current or expected) are not influencing the decision to take the drug, then one would expect to find a negative relationship between first taking Zyprexa and all other Medicaid spending. But the insignificantly positive estimate for the Zyprexa indicator variable presented in column (7) casts doubt on this hypothesis, as other Medicaid spending does not decline following the shift to this new drug. The results summarized in column (9) imply that total Medicaid spending increases substantially after the shift to Zyprexa. The significant estimate of \$896 implies more than a 32\% increase in health care spending (from an average of \$2754) after the first Zyprexa prescription and it suggests that Medicaid spending increases virtually one-forone with spending on this drug.

Of course, if drug treatment decisions are to some extent influenced by changes in health then this estimate will be misleading. This type of endogeneity might be less of a concern for Medicaid recipients first taking Zyprexa shortly after it is approved. For many of these "early adopters", the first prescription would plausibly be driven by a change in its availability rather than a change in health. I therefore differentiate between the 306 Medicaid recipients in the sample who take Zyprexa in the first twelve months that it is marketed and the 1229 who first take it in October of 1997 or later when estimating the average change in each outcome variable of interest that follows the first prescription. In the even-numbered columns, I summarize specifications in which EARLY ZYPREXA is equal to the ZYPREXA indicator for the early adopters and LATE ZYPREXA is equal to ZYPREXA for the late adopters.

The results for all other Medicaid spending in column (8) are quite interesting. For those shifted to the drug shortly after its approval, the significantly negative estimate of -307 on the EARLY ZYPREXA coefficient implies that spending on other types of medical care declined. This is consistent with the hypothesis that Zyprexa reduced the need for other types of medical care. ${ }^{28}$ The significantly positive estimate of 342 for LATE ZYPREXA in specification (8) implies that other Medicaid spending was significantly higher for late switchers following their first Zyprexa prescription. This suggests that a decline in health may have influenced the change in treatment for the typical individual in this group. For both groups, Medicaid spending is

${ }^{28}$ This result appears to be driven by a decline in spending on other drugs - see Table 8 . 
significantly higher after the shift to Zyprexa, as the results summarized in column (10) show. Thus even though Zyprexa may reduce the utilization of other types of medical care for the "early adopters", these savings appear not to be sufficiently large to offset the cost of Zyprexa.

While measuring spending from the Medicaid claims data is straightforward, estimating health from this same set of data is quite difficult because some dimensions of health may not be observable. I begin with two admittedly imperfect measures of health status. ${ }^{29}$ The first one is a dummy variable ANY IP/LTC that equals one if a person spends time in a hospital or a longterm care facility in the current period and zero otherwise. The second variable IP/LTC LOS is simply equal to the number of days that the Medicaid recipient spends in either type of institution. ${ }^{30}$ The small and insignificantly positive coefficient estimates for EARLY ZYPREXA in columns (12) and (14) suggest that - if changes in health were not correlated with taking Zyprexa for the early adopters - then the drug had relatively little impact on the probability of spending one or more nights in a health care facility. As before, the results are quite different for those first taking Zyprexa in October of 1997 or later. For this group, the probability of being institutionalized and the average number of days spent in a facility increases significantly following the first Zyprexa prescription.

The results presented in Tables 7B and 7C suggest a similar spending pattern for those switched to Risperdal and Seroquel following their market entries in January of 1994 and October of 1997, respectively. For both drugs, Medicaid expenditures increase significantly following the first prescription, though the implied effect is smaller for those shifted soon after the FDA approval than for individuals first taking the drug more than a year after it was approved. The implied effects on these two measures of health are less favorable for these two drugs than for Zyprexa, and in both cases the strong negative relationship between health and the first prescription remains for those shifted long after FDA approval.

\footnotetext{
${ }^{29}$ One obvious measure of health to consider is mortality. I do not examine this health outcome in this study because there is little evidence to suggest that these drugs could plausibly exert a significant effect on the mortality rate. As is clear from Appendix Table 1, there is actually an increase in the mortality rate during the time period studied, though this could largely be driven by the change in the age distribution of the sample.

${ }^{30}$ Lichtenberg's (2001) evidence suggests that - on average - the use of newer prescription drugs reduces the number of days that individuals spend in the hospital, thus at least partially offsetting the cost of the new drugs.
} 
In the specifications summarized in Table 8 , I investigate the timing of the change in Medicaid spending and individual health more carefully. The variable FIRST SCRIPT equals one in the first quarter that the individual takes Zyprexa and zero otherwise. PRE $t$ ZYPREXA is set to one $\mathrm{t}$ quarters before the first Zyprexa prescription and zero otherwise, while POST $\mathrm{t}$ ZYPREXA equals one $\mathrm{t}$ periods after the first treatment and zero otherwise. This table summarizes specifications for seven different outcome variables and there are two sets of coefficient estimates - one for early adopters and the other one for late adopters.

The first two columns summarize the results from the ANY ZYPREXA specification. The estimates of 0.822 and .727 on the POST1 coefficients imply that approximately $18 \%$ and $27 \%$, respectively, of the early and late adopters who take the drug in quarter $\mathrm{t}$ have stopped taking it within just a few months. Similarly, the estimates for POST4+ imply that just $61 \%$ and $54 \%$ of the two groups are still taking the drug in the average quarter four or more quarters later. Thus it is clear that a large fraction of individuals try the drug but then choose to stop taking it, perhaps switching to another anti-psychotic drug or taking no drug at all.

The third specification investigates the relationship between taking Zyprexa and spending on all other prescription drugs. The statistically significant difference of more than $\$ 330$ between the estimates for PRE1 and POST1 for the early adopters imply that quarterly Medicaid spending on other drugs declined substantially after individuals first took Zyprexa. An examination of spending for Clozaril and Risperdal demonstrates that virtually all of the change is caused by a decline in spending for these two potential substitute drugs. Thus the Zyprexa treatment indicator is itself negatively related with the Clozaril and Risperdal treatment variables, and the estimates imply that each additional dollar in spending on Zyprexa lowered spending on other drugs by approximately forty cents. The decline in spending on other drugs is just one-third as large for the late adopters, suggesting a decline of just fifteen cents for every dollar spent on Zyprexa.

To investigate whether a change in health appeared to - on average - precede or coincide with the decision to take Zyprexa, I test in the fourth and fifth specifications whether Medicaid spending on either inpatient or outpatient services was trending prior to Medicaid recipients' first prescription for Zyprexa. For both groups, Medicaid spending on both inpatient and outpatient care was increasing even before the first prescription, casting doubt on the hypothesis that the decision to treat is uncorrelated with a change in health for either group. Consistent with this, 
the fraction of "early adopters" hospitalized or in a long term care facility increases by 10.3 percentage points in the nine months leading up to the first Zyprexa prescription, with an even larger increase of 15.4 percentage points for late adopters.

For both groups, total Medicaid spending is significantly higher one year after the first Zyprexa prescription than it was just nine months before, with the difference of 714 in quarterly spending for late adopters substantially greater than the corresponding difference of 522 for early adopters. Similarly, neither group is less likely to be hospitalized. But given the significant change in outcome variables that either preceded or coincided with the change in drug treatment, it is not obvious how much of the change can be attributed to Zyprexa versus a change in health or some other factor. Section 6 below probes further on this issue by comparing the evolution of spending and utilization both before and after schizophrenia hospitalizations in 1994 (before the three atypical anti-psychotics studied here had diffused widely) and 2000 and examining changes in the distribution of health care spending and utilization during the study period.

\section{The Incidence of Adverse Side Effects}

The number of days spent in a hospital is clearly an imperfect measure of health, and thus in Table 9 I explore the effect of atypical anti-psychotic drugs on an additional set of outcome measures. Perhaps the most widely cited benefit of atypical anti-psychotic drugs when compared with the conventional anti-psychotics that preceded them is a reduction in the incidence of tardive dyskinesia and other extrapyramidal side effects (EPS). To measure the incidence of this side effect, I construct a variable that is equal to one if a Medicaid recipient has one or more Medicaid claims in the current quarter with EPS as a primary diagnosis and is zero otherwise. The summary statistics from Table 4 demonstrate that the prevalence of this adverse side effect has increased during the nine-year study period despite a sharp increase in the fraction of schizophrenia patients using atypical anti-psychotics. And consistent with this, the three sets of coefficient estimates displayed in the first column of Table 9 strongly suggest that none of the three major atypical anti-psychotic drugs has lowered the incidence of this adverse side effect.

While atypical anti-psychotics are believed to lower the incidence of EPS, a number of recent studies suggest that they may increase the risk of other adverse effects, including abnormal weight gain and diabetes, which are associated with an increased risk of heart disease. The next two sets of specifications examine the relationship between taking atypical antipsychotics and the incidence of these two adverse effects. While the results for abnormal weight 
gain are mixed, the diabetes results are fairly consistent. For all three drugs, the probability that late adopters are diagnosed with this condition (which could itself be caused by weight gain) increases significantly after first taking the drug. Once again, this may not be surprising given that the incidence of diabetes in the schizophrenia sample increased by $85 \%$ from 1993 to 2001 (from $3.1 \%$ to $5.8 \%$ - see Table 4). The next two columns of results explore the relationship of the three drugs with two other side effects previously explored in the literature (any epileptic symptoms and cognitive or motor impairment), ${ }^{31}$ and the last column lists estimates from three separate specifications that investigate whether atypical anti-psychotics are significantly related to the incidence of any of these five side effects. Given that all six of the estimates in this final column are positive (with two significantly so), it appears that if anything the shift to atypical anti-psychotics has been associated with an increase in the incidence of adverse side effects.

Taken together, this first set of results suggests that Zyprexa, Risperdal, and Seroquel have led to a sharp increase in health care spending but have not led to significant improvements in the health of schizophrenia patients, as measured by the number of days spent in a health care facility or the incidence of adverse side effects. This may not be surprising given that average spending on anti-psychotic drugs in the schizophrenia sample increased by a factor of six and yet there was no decline in the hospitalization rate and the incidence of adverse side effects rose substantially (Table 4). But the fact that changes in health may coincide with the change in treatment regimen suggests that the results should be interpreted with some caution. In the next section, I propose two alternative strategies for estimating the effect of this new category of drug treatments on government spending and health outcomes.

\section{Two Alternative Strategies for Estimating the Effect of Drug Treatments}

\section{A. A Cohort Analysis -Spending and Outcomes for Schizophrenia Patients in 1994 and 2000}

The results from the previous section examined how outcome variables changed for individuals after their first Zyprexa, Risperdal, or Seroquel prescriptions relative to their counterparts who took the drug in a later period or never took the drug. One clear limitation of the individual fixed effects analyses was that changes in health appeared to precede or coincide with the shift to atypical treatments for many Medicaid recipients. Thus any pre-post comparison of spending, utilization, or health outcomes will inevitably confound the effect of the

${ }^{31}$ Epilepsy includes ICD-9 codes beginning with 345 while cognitive or motor impairment includes 3154 (coordination disorder), 7810 (abnormal involuntary movements), 7813 (lack of 
drug treatments with this other factor if the change in health that influenced the treatment decision is at least to some extent persistent.

One alternative strategy for estimating the impact of Zyprexa and other atypical antipsychotics is to compare the trajectory of outcome variables for a well-defined group when these three new prescription drugs were available to a similar group before they had yet hit the market. In this section, I do this by comparing pre-post patterns of Medicaid expenditures and health for individuals hospitalized with a primary diagnosis of schizophrenia in the third quarter of 1994 and the third quarter of 2000. I choose the third quarter of 1994 because the claims data for the last quarter of 1993 appear to be incomplete (with 1-2 weeks of claims missing), and this allows me to have two quarters of accurate pre-hospitalization data. Unfortunately, Risperdal is therefore available throughout the first period, but given that the drug had not diffused to a significant extent at that point it should not be too problematic for the comparison.

Before proceeding to this analysis, there are two important caveats. First, it is possible that the Medicaid recipients hospitalized in the third quarter of 1994 are to some extent different from those hospitalized with schizophrenia six years later (e.g. younger). Second, anti-psychotic drugs are not the only medical care treatments that are changing during this time period, and thus other factors may be partially responsible for any observed differences between the two groups.

Table 10A provides summary statistics for the 196 individuals in the sample hospitalized with a primary diagnosis of schizophrenia during the third quarter of 1994 . For this group, the average number of days hospitalized increases by 9.6 from quarter two to three, and then falls by 9.3 from the third to fourth quarter. Spending one quarter after the hospitalization is $\$ 276$ lower than it was in the previous quarter. Both the number of hospital days and total Medicaid spending continue to trend down in the subsequent two quarters, with the number of days hospitalized falling by more than 50\% from the fourth quarter of 1994 to the second quarter of 1995. Approximately $15 \%$ of individuals in this group are taking Risperdal in a typical quarter both before and after the hospitalization, with none taking Zyprexa or Seroquel because the drugs had not yet reached the market.

Table 10B lists the corresponding summary statistics for the 235 individuals hospitalized in the third quarter of 2000 with a primary diagnosis of schizophrenia. The average number of inpatient days just before, during, and immediately after the third quarter are quite similar to coordination), 3140 (attention deficit disorder), and 3101 (organic personality syndrome). 
those described above, with an increase of 10.5 from the second to third quarter and a decline of 10.0 from the third to fourth quarter. Similarly, average Medicaid spending is $\$ 167$ lower one quarter after the hospitalization than it was just one quarter earlier, which is slightly lower than the corresponding decline for the 1994 group. Rather than continuing to trend down as they did for the earlier cohort, Medicaid spending and the number of days hospitalized remains fairly constant in the subsequent two quarters (2001 quarters 1 and 2). The fraction of this group taking Risperdal, Zyprexa, or Seroquel is 4-5 times as large as it was just six years earlier, yet if anything it appears that the time spent in the hospital for acute episodes of schizophrenia has increased. Thus it seems unlikely that the sharp increase in anti-psychotic drug spending has reduced the hospitalization rate below what it otherwise would have been.

Because these two groups account for less than $7 \%$ of the more than 3000 Medicaid recipients diagnosed with schizophrenia in each year, it is possible that focusing exclusively on those who are hospitalized gives a very inaccurate picture of the changes in outcome variables of interest during the time period of interest. Thus in Table 11, I examine distributions of outcomes variables for all individuals with a primary diagnosis of schizophrenia in 1994 and 2001. This gives me a sample of 3083 Medicaid recipients in 1994 and 3469 seven years later. I assign each Medicaid recipient to a decile based on his/her spending in the relevant year, and compare changes in total Medicaid spending, anti-psychotic drug spending, the fraction with one or more "RZS" prescriptions, the fraction hospitalized at least once, and the fraction diagnosed with one or more of the five side effects described above.

As shown in the first two columns of the table, the changes in Medicaid spending are substantial for all deciles of the distribution. For example, total spending increases by $112 \%$ in decile 2 , by $107 \%$ in decile 5 , by $55 \%$ in decile 8 , and by $41 \%$ overall. More than $53 \%$ of the increase in average annual spending is attributable to the $266 \%$ increase in spending on antipsychotic drugs, which rises from $\$ 782$ in 1994 to $\$ 2863$ by 2001 . By 2001, nearly 7 out of every 10 individuals diagnosed with schizophrenia consumes one or more Risperdal, Zyprexa, or Serouqel prescriptions, compared with just $12.5 \%$ who took Risperdal seven years earlier.

The next two columns compare hospitalization rates for the 1994 and 2001 groups. Overall, the fraction of individuals hospitalized remains fairly constant, falling from $36.7 \%$ in 1994 to $36.0 \%$ in 2001 . Interestingly, there are increases in all five of the low-spending deciles and corresponding declines in the five high-spending deciles. This may largely reflect a change 
in the price of hospital care relative to prescription drugs. In the earlier period, a hospitalization almost guaranteed a position high in the spending distribution, but this is less true seven years later when individuals spend substantially more on prescription drugs, and thus a larger fraction of hospitalized individuals now fall into the low-spending deciles.

The final two columns provide a quite striking set of results. Overall, the fraction of Medicaid schizophrenia patients diagnosed with one of the five side effects described above increases by $54 \%$ from $12.6 \%$ in 1994 to $19.4 \%$ in 2001 , and this increase is statistically significant in nine out of ten deciles. While it is certainly possible that health care providers have become more likely to test for (and thus more likely to diagnose) these adverse side effects in their patients, it seems implausible that this can explain all of the observed increase.

Taken together, the results presented in this section strongly suggest that the sharp increase in government spending for anti-psychotic drugs has not lowered the utilization of other medical care services nor improved observed measures of health. If anything, it appears that the drugs have led to an increase in the incidence of adverse side effects, with much of the increase driven by a more than $90 \%$ increase in the fraction diagnosed with diabetes. But given that the characteristics of schizophrenia patients and other medical care practice patterns may be changing during this time period, this cohort analysis is not without its limitations.

B. IV Estimation: Exploiting Variation across Psychiatrists in the Probability of Drug Treatment

My final strategy for estimating the effect of atypical anti-psychotic drugs on Medicaid spending and health outcomes is to utilize instrumental variables that influence treatment decisions but are unlikely to exert an independent effect on outcome variables. One candidate is the Medicaid recipient's psychiatrist, ${ }^{32}$ as some providers may be more likely than others to prescribe a drug for the same patient. To explore whether the patient's psychiatrist would provide useful variation, I begin by estimating the probability of taking Zyprexa for all individuals who visited a psychiatrist at least once in the year before this drug first hit the market. If the Medicaid recipient visits more than one psychiatrist during this time, I pair him or her with the psychiatrist whose appointment date is closest to October of 1996. I assign Medicaid recipients to their pre-Zyprexa release psychiatrist rather than to the ones they visited after the release of Zyprexa because of a concern that individuals may switch psychiatrists

\footnotetext{
${ }^{32}$ See Hellerstein (1998) for an examination of the variation across physicians in prescribing patterns.
} 
because of a change in health or because they learn that certain psychiatrists are more willing to prescribe this new drug.

To increase the number of observations that I have for each psychiatrist, I use a $25 \%$ sample of Medicaid recipients here rather than the 5\% sample used above. In this larger sample, there are 7144 individuals with one or more visits to a psychiatrist with a primary diagnosis of schizophrenia in the year before the release of Zyprexa. ${ }^{33}$ I restrict attention to the Medicaid recipients between the ages of 18 and 64 who never reside in a COHS county and are eligible for Medicaid during all three months of the third quarter of 1996. Additionally, I consider only those recipients who are paired with one of the 95 psychiatrists with 15 or more patients in my data, and this leaves me with a sample of approximately 3000 Medicaid recipients.

In the odd-numbered columns of Table 12, I summarize the results from three different probit specifications. The dependent variables in this table are indicator variables that equal one if the recipient had one or more Zyprexa prescriptions in a particular time period and zero otherwise. The findings here demonstrate that individuals who visited the psychiatrist fairly frequently in the year leading up to the release of Zyprexa or who were admitted to the hospital one or more times with a primary diagnosis of schizophrenia were more likely to take the drug in the year or two after its release. These specifications also control for the age and the gender of the Medicaid recipient and include ten diagnosis-specific fixed effects to control for potential differences in the appropriateness of the drug for each type of schizophrenia.

To estimate the importance of the psychiatrist in the treatment decision after controlling for these observable measures of the patient's health, I calculate the variable PSYCHIATRIST DIFF as follows for each recipient (j) - psychiatrist (k) pair:

$$
\text { (8) PSYCHIATRIST DIFF } j k=\frac{\sum_{i=1}^{N_{k}}\left(Z_{i k}-\hat{P}_{i k}\right)-\left(Z_{j k}-\hat{P}_{j k}\right)}{N_{k}-1}
$$

with $Z_{\text {ik }}$ equal to 1 if recipient $i$ takes the drug in a particular time period and 0 otherwise, $\hat{P}_{i k}$ representing the predicted probability that patient $\mathrm{i}$ will take the drug treatment, and $\mathrm{N}_{\mathrm{k}}$ equal to the number of patients for this psychiatrist. This variable simply measures the difference

\footnotetext{
${ }^{33}$ Most of the individuals diagnosed with schizophrenia do not have an appointment with a psychiatrist during the course of a year but instead obtain services from mental health clinics or other outpatient facilities.
} 
between the fraction of psychiatrist k's patients who took the drug and the proportion one would have expected using the probit results to predict each individual's treatment probability. I exclude person $\mathrm{j}$ from this calculation to avoid a mechanical relationship between $\mathrm{j}$ 's treatment decision and the psychiatrist effect.

I then re-estimate the probit equations including this psychiatrist-specific effect. The coefficient estimates for PSYCHIATRIST DIFF in the even-numbered columns are significantly positive in every case, suggesting that certain psychiatrists are much more likely than others to prescribe this drug even after controlling for several observable measures of each Medicaid recipient's pre-treatment health. Whether this is due to differential advertising by pharmaceutical firms or some other factor is not obvious from these results.

I then use the three sets of psychiatrist fixed effects (estimated using the 1997, 1998, and 1997-98 specifications summarized in Table 12) to explore the effect of Zyprexa on Medicaid spending in each of the three periods in Table 13. In the odd-numbered columns I instrument for an indicator variable that equals one if the recipient takes Zyprexa in a certain year and zero otherwise, while in the even-numbered columns I instrument instead for the number of Zyprexa prescriptions in each time period. For all six regressions, I include the first stage estimate for the PSYCHIATRIST DIFF variable and the corresponding OLS estimates for the dependent variables of interest.

In all six specifications, the coefficient estimate on taking Zyprexa or on the number of Zyprexa prescriptions is positive, suggesting that this drug leads to a substantial increase in Medicaid spending and does not lead to reductions in other health care utilization that more than offset the additional spending. In four out of six specifications, the coefficients are not precisely estimated. This lack of precision may be due to the small number of patients for each psychiatrist or because Medicaid recipients with schizophrenia frequently change psychiatrists.

Adding this set of results to the ones using individual fixed effects and cohort comparisons, it appears that the new and much more expensive anti-psychotic drugs used to treat schizophrenia have not led to sharp improvements in health and reductions in the utilization of other medical care that justify the additional spending.

\section{Conclusion}

During the last eight years, government spending on anti-psychotic drugs has increased by $670 \%$ and now exceeds spending in any other therapeutic category. This increase was caused 
by a shift to a new category of drugs known as atypical anti-psychotics, which are substantially more expensive than the conventional anti-psychotics that preceded them. The findings in this paper suggest that the health benefits of these new drugs are not large, though it is worth noting that there may be improvements in other dimensions of health that are not captured by the several that I consider. If anything, my results suggest that schizophrenia patients have become less healthy after taking the new drugs, with the incidence of diabetes increasing following the shift to Risperdal, Zyprexa, and Seroquel.

In the current study I do not examine the effect of atypical anti-psychotic drugs on labor supply because I do not have earnings or labor force participation data for Medicaid recipients. ${ }^{34}$ While it is certainly possible that atypical anti-psychotic drugs improve cognition and increase the ability of individuals with schizophrenia to work, any rise in pharmaceutical prices caused by the Medicaid program may increase the value of public health insurance, thus discouraging individuals from working. The fact that the number of individuals diagnosed with mental illness who are receiving SSI (and thus Medicaid), which essentially requires labor force nonparticipation, has increased by more than $135 \%$ during the last decade suggests that new drugs have not on average increased labor supply among those with serious mental illnesses, though this may reflect an effect of SSI incentives rather than an effect of Medicaid coverage. Additionally, there is little evidence that the exit rate from my Medicaid sample increased following the diffusion of the new drugs.

As government purchasing of prescription drugs continues to increase, either because of a Medicare prescription drug benefit or because of further growth in Medicaid and state subsidy programs, pharmaceutical prices may become a much less accurate measure of the value of these treatments to the patients who consume them. This will be especially true for treatments with relatively few private customers like the anti-psychotic drugs studied here. Estimating the effect of Medicaid and other government programs on pricing, product proliferation, and innovation in the pharmaceutical industry clearly represents an important area for future work.

\footnotetext{
${ }^{34}$ See Berndt, et al (1998) and Finkelstein, et al (1996) for studies of the effect of antidepressants on work performance.
} 


\section{References}

Autor, D.H. and Duggan, M.G. "The Rise in the Disability Rolls and the Decline in Unemployment," Quarterly Journal of Economics, February, 2003.

Berndt ER, Bir A, Busch SH, Frank RG, Normand S-LT. (2002) “ The Medical Treatment of Depression, 1991-1996: productive inefficiency, expected outcome variations, and price indexes." Journal of Health Economics, 21(3): 373-396.

Berndt, E.R., Finkelstein, S.N., Greenberg, P.E., et. al. (1998). "Workplace Performance Effects from Chronic Depression and Its Treatment." Journal of Health Economics, 17(5), 511-535.

Carpenter, W. and Gold, J. "Another View of Therapy for Cognition in Schizophrenia." Biological Psychiatry, 51, 969-971.

Cutler, D., McClellan, M.B., Newhouse, J.P., and Remler, D. (1998). "Are Medical Prices Falling?" Quarterly Journal of Economics, 113(4), 991-1024.

Cutler, D. and McClellan, M.B. (2001). "Is Technological Change in Medicine Worth It?" Health Affairs.

Duggan, M.G. (2002). "Does Contracting out Increase the Efficiency of Government Programs? Evidence from Medicaid HMOs." NBER Working Paper No. 9091.

Finkelstein, S. N., Berndt, E.R., Greenberg, P.E., et. al. (1996). "Improvement in Subjective Work Performance after Treatment of Chronic Depression: Some Preliminary Results," Psychopharmacology Bulletin, 32(1), 33-40.

Gianfrancesco, F.D., Grogg, A.L., Mahmoud, R.A., et. al. (2002). "Differential Effects of Risperidone, Olanzapine, Clozapine, and Conventional Antipsychotics on Type 2 Diabetes: Findings from a Large Health Plan Database.” Journal of Clinical Psychiatry, 63(10), 920-930.

Hellerstein, J., (1998) “The Importance of the Physician in the Generic Versus Trade-Name Prescription Decision,” RAND Journal of Economics.

Keefe R.S., Silva, S.G., Perkins, D.O., Lieberman, J.A. (1999). “The Effects of Atypical Antipsychotic Drugs on Neurocognitive Impairment in Schizophrenia: A Review and Metaanalysis." Schizophrenia Bulletin, 25(2), 201-222.

Lamberg, L. (1998). "New Medications Aid Cognition in Schizophrenia," Journal of the American Medical Association, 280(11), 953-954.

Leucht, G. Pitschel-Walz, D., and W. Kissling (1999) "Efficacy and Extrapyramidal Side-Effects of The New Anti-Psychotics Olanzapine, Quetiapine, Risperidone, and Sertindole Compared to Conventional Anti-Psychotics and Placebo. A Meta-Analysis of Randomized Controlled Trials." Schizophrenia Research, 35(1), 51-68. 
Lichtenberg, F.R. (2001). "Are the Benefits of Newer Drugs Worth Their Cost? Evidence from the 1996 MEPS." Health Affairs, 20(5), 241-251.

Licthenberg, F.R. (1996). "Do More (and Better) Drugs Keep People Out of Hospitals?" American Economic Review Papers and Proceedings, 384-388.

McClellan, M.B., McNeil, B.J., and Newhouse, J.P. (1994). "Does More Intensive Treatment of Acute Myocardial Infarction Reduce Mortality?" Journal of the American Medical Association, 272(11), 859-66.

Meltzer, H.Y., Park, S. and Kessler, R. (1999). "Cognition, Schizophrenia, and the Atypical Antipsychotic Drugs." Proceedings of the National Academy of Sciences of the USA, 96 (24), 13591-13593.

National Institute for Health Care Management Research and Educational Foundation, "Prescription Drug Expenditures in 2001: Another Year of Escalating Costs," (May, 2002).

Scott-Morton, F. (1998). "The Strategic Response by Pharmaceutical Firms to the Medicaid Most-Favored-Customer Rules.” RAND Journal of Economics, 28(2), 269-290.

Sernyak, M.J., Leslie, D.L., Alarcon, R.D., et. al. (2002). “Association of Diabetes Mellitus with Use of Atypical Neuroleptics in the Treatment of Schizophrenia." American Journal of Psychiatry, 159(4), 561-566.

Social Security Administration. "Annual Statistical Supplement," Social Security Bulletin, various years.

Wennberg, J.E. and Cooper, M.M. (1999). "The Quality of Medical Care in the United States: A Report on the Medicare Program." The Dartmouth Atlas of Health Care in the United States, American Health Association Press, Chicago. 


\begin{tabular}{|c|c|c|c|c|c|c|}
\hline & \multicolumn{2}{|c|}{$\begin{array}{l}\text { Expenditures } \\
\text { (in millions) }\end{array}$} & \multicolumn{2}{|c|}{$\begin{array}{l}\text { Prescriptions } \\
\text { (in millions) }\end{array}$} & \multicolumn{2}{|c|}{ Avg. Cost } \\
\hline & 1996 & 2001 & 1996 & 2001 & 1996 & 2001 \\
\hline Central Nervous System & 1991 & 6000 & 44.9 & 73.4 & $\$ 44$ & $\$ 82$ \\
\hline Cardiovascular-Renal & 1622 & 2386 & 51.4 & 75.0 & $\$ 32$ & $\$ 32$ \\
\hline Antimicrobials & 1534 & 2706 & 38.1 & 43.6 & $\$ 40$ & $\$ 62$ \\
\hline Gastrointestinals & 1369 & 1881 & 19.1 & 24.7 & $\$ 72$ & $\$ 76$ \\
\hline Hormones / Hormonal Mech & 869 & 2088 & 27.6 & 43.7 & $\$ 31$ & $\$ 48$ \\
\hline Respiratory Tract & 818 & 1840 & 29.9 & 45.9 & $\$ 27$ & $\$ 40$ \\
\hline Relief of Pain & 762 & 2095 & 33.1 & 48.4 & $\$ 23$ & $\$ 43$ \\
\hline Neurologics & 671 & 1567 & 18.4 & 29.7 & $\$ 37$ & $\$ 53$ \\
\hline Metabolics / Nutrients & 469 & 1289 & 13.4 & 25.6 & $\$ 35$ & $\$ 50$ \\
\hline Hematologics & 350 & 802 & 6.1 & 10.3 & $\$ 57$ & $\$ 78$ \\
\hline Skin / Mucous Membranes & 280 & 334 & 10.4 & 9.9 & $\$ 27$ & $\$ 34$ \\
\hline Oncolytics & 251 & 474 & 3.4 & 4.0 & $\$ 73$ & $\$ 118$ \\
\hline Immunologics & 156 & 424 & 0.3 & 0.7 & $\$ 457$ & $\$ 622$ \\
\hline Ophthalmics & 151 & 293 & 5.9 & 8.1 & $\$ 25$ & $\$ 36$ \\
\hline Unclassified / Miscellaneous & 99 & 464 & 1.5 & 2.1 & $\$ 67$ & $\$ 221$ \\
\hline Otics & 97 & 140 & 6.0 & 7.0 & $\$ 16$ & $\$ 20$ \\
\hline Anti-Parasitics & 39 & 53 & 1.9 & 2.2 & $\$ 21$ & $\$ 24$ \\
\hline Anesthetics & 22 & 36 & 0.5 & 0.6 & $\$ 43$ & $\$ 58$ \\
\hline Antidotes & 13 & 28 & 0.1 & 0.2 & $\$ 132$ & $\$ 113$ \\
\hline Contrast Media / Radiopharm & 0 & 2 & 0.0 & 0.0 & $\$ 23$ & $\$ 45$ \\
\hline Missing & 1154 & 632 & 70.9 & 26.2 & $\$ 16$ & $\$ 24$ \\
\hline Total (with double-counting) & 12719 & 25534 & 382.9 & 481.4 & $\$ 33$ & $\$ 53$ \\
\hline Total (no double-counting) & 12296 & 24577 & 366.9 & 462.5 & $\$ 34$ & $\$ 53$ \\
\hline
\end{tabular}

Dollars on spending and number of prescriptions by drug were obtained from the Center for Medicare and Medicaid Services State Drug Utilization Data. The therapeutic category for each drug was obtained from the FDA's National Drug Code directory. In some cases, a drug was not listed in the FDA files - these drugs are in the "Missing" category. Dollar values are inflation-adjusted to 2001 dollars. 
Table 2A: Central Nervous System Drug Utilization by Medicaid: 1996 and 2001

\begin{tabular}{ccccccc} 
& \multicolumn{2}{c}{ Expenditures (millions) } & Prescriptions (millions) & \multicolumn{2}{c}{ Average Cost } \\
& 1996 & 2001 & 1996 & 2001 & 1996 & 2001 \\
Anti-Psychotic Drugs & $\$ 819$ & $\$ 3,007$ & 13.3 & 19.9 & $\$ 61$ & $\$ 151$ \\
Anti-Depressants & $\$ 766$ & $\$ 1,879$ & 15.8 & 29.2 & $\$ 48$ & $\$ 64$ \\
Anti-Anxiety & $\$ 202$ & $\$ 375$ & 9.4 & 11.7 & $\$ 21$ & $\$ 32$ \\
All Other CNS & $\$ 269$ & $\$ 791$ & 8.4 & 14.3 & $\$ 32$ & $\$ 56$ \\
Data were obtained from the Center for Medicare and Medicaid Services (CMS) and the FDA.
\end{tabular}

Table 2B: Medicaid Anti-Psychotic and Anti-Depressant Market Shares

$\begin{array}{cccccc}\text { Drug } & \text { Number } & \text { Mkt Share } & \text { Drug } & \text { Number } & \text { Mkt Share } \\ \text { Zyprexa } & 4.73 & 74 \% & \text { Zoloft } & 4.62 & 18 \% \\ \text { Risperdal } & 5.67 & 78 \% & \text { Paxil } & 4.54 & 18 \% \\ \text { Seroquel } & 1.99 & 63 \% & \text { Prozac } & 2.87 & 17 \%\end{array}$

Data were obtained from the CMS and the National Institute for Health Care Management.

\begin{tabular}{|c|c|c|c|c|c|}
\hline \multicolumn{2}{|c|}{ Total Paid $\left({ }^{*} 1000\right)$} & \multicolumn{2}{|c|}{ Scripts (Millions) } & \multicolumn{2}{|c|}{ Average Cost } \\
\hline 1996 & 2001 & 1996 & 2001 & 1996 & 2001 \\
\hline$\$ 12$ & $\$ 1,330$ & 0.06 & 4.73 & $\$ 208$ & $\$ 281$ \\
\hline$\$ 336$ & $\$ 890$ & 2.10 & 5.67 & $\$ 160$ & $\$ 157$ \\
\hline$\$ 0$ & $\$ 335$ & 0.00 & 1.99 & - & $\$ 168$ \\
\hline$\$ 248$ & $\$ 135$ & 2.74 & 1.04 & $\$ 90$ & $\$ 130$ \\
\hline$\$ 86$ & $\$ 81$ & 1.24 & 0.76 & $\$ 69$ & $\$ 106$ \\
\hline$\$ 109$ & $\$ 218$ & 5.64 & 5.60 & $\$ 19$ & $\$ 39$ \\
\hline$\$ 791$ & $\$ 2,990$ & 11.78 & 19.78 & $\$ 67$ & $\$ 151$ \\
\hline
\end{tabular}

Table 2D: Medicaid Spending and Number of Prescriptions for Zyprexa in 2001

$\begin{array}{lcccccc}\text { NDC } & \text { Dosage } & \text { Paid }\left({ }^{*} 1000\right) & \text { \# Scripts } & \text { Avg Paid } & \text { FDA } & \text { Enter } \\ 24117 & 10 \mathrm{MG} & \$ 693,691 & 1900017 & \$ 365 & 9 / 96 & 9 / 96 \\ 24115 & 5 \mathrm{MG} & \$ 271,162 & 1319155 & \$ 206 & 9 / 96 & 9 / 96 \\ 24415 & 15 \mathrm{MG} & \$ 154,547 & 390768 & \$ 395 & 9 / 97 & 1 / 00 \\ 24112 & 2.5 \mathrm{MG} & \$ 142,127 & 878931 & \$ 162 & 5 / 97 & 5 / 97 \\ 24116 & 7.5 \mathrm{MG} & \$ 76,333 & 344362 & \$ 222 & 9 / 96 & 9 / 96 \\ 24420 & 20 \mathrm{MG} & \$ 41,272 & 88101 & \$ 468 & 9 / 97 & 12 / 00 \\ 24454 & 10 \mathrm{MG} & \$ 9,312 & 24805 & \$ 375 & 4 / 00 & 8 / 00 \\ 24453 & 5 \mathrm{MG} & \$ 6,135 & 27206 & \$ 225 & 4 / 00 & 8 / 00 \\ 24455 & 15 \mathrm{MG} & \$ 78 & 176 & \$ 440 & 4 / 00 & 9 / 01 \\ 24456 & 20 \mathrm{MG} & \$ 64 & 117 & \$ 553 & 4 / 00 & 9 / 01\end{array}$

Data were obtained from CMS. 
Table 3A: Medicaid Spending on Anti-Psychotic Drugs in 5\% CA Sample: 1993-2001

\begin{tabular}{|c|c|c|c|c|c|c|c|c|}
\hline & \multicolumn{4}{|c|}{ Schizophrenia Sample } & \multicolumn{4}{|c|}{ All Medicaid Recipients } \\
\hline Year & \# Claims & $\% R, Z, S$ & Paid $(* 1000)$ & Avg Paid & \# Claims & $\% R, Z, S$ & Paid $\left({ }^{*} 1000\right)$ & Avg Paid \\
\hline 1993 & 37741 & $0.0 \%$ & $\$ 1,855$ & $\$ 49$ & 74741 & $0.0 \%$ & 2731 & $\$ 36$ \\
\hline 1994 & 46739 & $4.8 \%$ & $\$ 2,771$ & $\$ 59$ & 86086 & $3.4 \%$ & 3855 & $\$ 45$ \\
\hline 1995 & 48809 & $7.1 \%$ & $\$ 3,266$ & $\$ 67$ & 86337 & $5.1 \%$ & 4379 & $\$ 51$ \\
\hline 1996 & 51652 & $9.0 \%$ & $\$ 3,671$ & $\$ 71$ & 83543 & $7.0 \%$ & 4610 & $\$ 55$ \\
\hline 1997 & 53436 & $16.5 \%$ & $\$ 4,834$ & $\$ 91$ & 82390 & $14.1 \%$ & 5989 & $\$ 73$ \\
\hline 1998 & 57571 & $31.8 \%$ & $\$ 7,648$ & $\$ 133$ & 90240 & $30.8 \%$ & 10113 & $\$ 112$ \\
\hline 1999 & 59990 & $40.5 \%$ & $\$ 9,820$ & $\$ 164$ & 96216 & $41.1 \%$ & 13645 & $\$ 142$ \\
\hline 2000 & 60652 & $47.6 \%$ & $\$ 11,182$ & $\$ 184$ & 107608 & $50.2 \%$ & 17333 & $\$ 161$ \\
\hline 2001 & 62291 & $53.3 \%$ & $\$ 12,612$ & $\$ 203$ & 116907 & $57.8 \%$ & 20952 & $\$ 179$ \\
\hline
\end{tabular}

Data were obtained from the California Department of Health Services' 5\% Medicaid claims sample. The first four columns summarize information for the schizophrenia sample only, while the final four include information for all Medicaid recipients in the $5 \%$ sample. \% R,Z,S is equal to the percentage of anti-psychotic prescriptions for Risperdal, Zyprexa, or Seroquel.

Table 3B: Medicaid Spending on Top Four Anti-Psychotics in Schizophrenia Sample: 1993-2001

\begin{tabular}{|c|c|c|c|c|c|c|c|c|}
\hline \multirow[b]{2}{*}{ Year } & \multicolumn{2}{|c|}{ Clozaril } & \multicolumn{2}{|c|}{ Risperdal } & \multicolumn{2}{|c|}{ Zyprexa } & \multicolumn{2}{|c|}{ Seroquel } \\
\hline & \# Claims & Avg Paid & \# Claims & Avg Paid & \# Claims & Avg Paid & \# Claims & Avg Paid \\
\hline 1993 & 7686 & $\$ 102$ & 0 & - & 0 & - & 0 & - \\
\hline 1994 & 10133 & $\$ 101$ & 2248 & $\$ 233$ & 0 & - & 0 & - \\
\hline 1995 & 11206 & $\$ 100$ & 3487 & $\$ 261$ & 0 & - & 0 & - \\
\hline 1996 & 13390 & $\$ 96$ & 4479 & $\$ 261$ & 147 & $\$ 283$ & 0 & - \\
\hline 1997 & 12536 & $\$ 98$ & 5374 & $\$ 259$ & 3397 & $\$ 326$ & 17 & $\$ 208$ \\
\hline 1998 & 9797 & $\$ 111$ & 7182 & $\$ 251$ & 10076 & $\$ 344$ & 1057 & $\$ 194$ \\
\hline 1999 & 8538 & $\$ 120$ & 9058 & $\$ 251$ & 12831 & $\$ 370$ & 2407 & $\$ 221$ \\
\hline 2000 & 6502 & $\$ 126$ & 10863 & $\$ 247$ & 14331 & $\$ 381$ & 3687 & $\$ 243$ \\
\hline 2001 & 6610 & $\$ 131$ & 12404 & $\$ 246$ & 15471 & $\$ 391$ & 5306 & $\$ 254$ \\
\hline
\end{tabular}




\section{Table 4: Summary Statistics for Schizophrenia Sample}

\begin{tabular}{|c|c|c|c|c|c|c|}
\hline \multirow[b]{2}{*}{ Variable } & \multicolumn{3}{|c|}{ Full Sample } & \multicolumn{3}{|c|}{ Those with Schz Clms $>0$} \\
\hline & 1993Q1 & 1997Q1 & 2001Q1 & 1993Q1 & 1997Q1 & 2001Q1 \\
\hline Eligible Months & 2.94 & 2.94 & 2.96 & 2.97 & 2.97 & 2.98 \\
\hline Eligible Months on SSI & 2.44 & 2.59 & 2.77 & 2.89 & 2.86 & 2.90 \\
\hline Medicare Months & 1.02 & 1.12 & 1.20 & 1.30 & 1.26 & 1.19 \\
\hline Managed Care Months & 0.09 & 0.17 & 0.25 & 0.03 & 0.06 & 0.15 \\
\hline$\%$ Female $0-17$ & $3.1 \%$ & $1.9 \%$ & $0.8 \%$ & $0.2 \%$ & $0.4 \%$ & $0.4 \%$ \\
\hline$\%$ Female $18-44$ & $25.1 \%$ & $22.6 \%$ & $18.7 \%$ & $20.4 \%$ & $18.3 \%$ & $16.8 \%$ \\
\hline$\%$ Female $45-64$ & $14.0 \%$ & $16.3 \%$ & $20.0 \%$ & $16.8 \%$ & $18.8 \%$ & $19.8 \%$ \\
\hline$\%$ Female 65 plus & $7.4 \%$ & $7.4 \%$ & $7.4 \%$ & $7.8 \%$ & $6.9 \%$ & $5.3 \%$ \\
\hline$\%$ Male $0-17$ & $4.7 \%$ & $2.8 \%$ & $1.3 \%$ & $0.6 \%$ & $0.5 \%$ & $0.6 \%$ \\
\hline$\%$ Male $18-44$ & $31.6 \%$ & $29.7 \%$ & $27.2 \%$ & $37.8 \%$ & $33.6 \%$ & $30.3 \%$ \\
\hline$\%$ Male 45-64 & $11.6 \%$ & $16.2 \%$ & $21.2 \%$ & $14.2 \%$ & $18.9 \%$ & $24.0 \%$ \\
\hline$\%$ Male 65 plus & $2.5 \%$ & $3.0 \%$ & $3.4 \%$ & $2.3 \%$ & $2.6 \%$ & $3.0 \%$ \\
\hline Number Medicaid Eligibles & 5653 & 6180 & 5980 & 2329 & 2557 & 2496 \\
\hline \# that Die by End of Year & 35 & 87 & 127 & 26 & 38 & 33 \\
\hline \# that Die by End of 2001 & 712 & 531 & 127 & 333 & 223 & 33 \\
\hline \# that Leave before 2001Q4 & 829 & 791 & 194 & 308 & 271 & 55 \\
\hline SPENDING \& UTILIZATION & 1993Q1 & 1997Q1 & 2001Q1 & 1993Q1 & 1997Q1 & 2001Q1 \\
\hline$\%$ with Inpatient Stay & $9.4 \%$ & $10.1 \%$ & $10.6 \%$ & $13.8 \%$ & $14.7 \%$ & $15.5 \%$ \\
\hline \% with Long Term Care Stay & $5.0 \%$ & $6.1 \%$ & $7.1 \%$ & $7.0 \%$ & $6.1 \%$ & $6.7 \%$ \\
\hline$\%$ with Inpatient or LTC Stay & $13.7 \%$ & $15.3 \%$ & $16.3 \%$ & $19.7 \%$ & $20.0 \%$ & $20.6 \%$ \\
\hline Average Inpatient Days & 1.11 & 1.24 & 1.34 & 1.75 & 2.03 & 2.45 \\
\hline verage Long Term Care Days & 4.60 & 7.33 & 5.90 & 6.34 & 7.34 & 5.29 \\
\hline$\%$ with $1+R, Z, S$ Scripts & $0.0 \%$ & $9.4 \%$ & $42.3 \%$ & $0.0 \%$ & $15.9 \%$ & $60.0 \%$ \\
\hline Psychotic Medicaid RX Spending & 79 & 167 & 505 & 153 & 315 & 809 \\
\hline -Psychotic Medicaid RX Claims & 1.70 & 2.08 & 2.60 & 2.93 & 3.53 & 4.02 \\
\hline ther Medicaid RX Spending & 143 & 201 & 414 & 172 & 222 & 402 \\
\hline Other Medicaid RX Claims & 5.51 & 6.19 & 7.98 & 6.67 & 7.22 & 8.63 \\
\hline otal FFS Medicaid Spending & 1765 & 2113 & 2885 & 2500 & 2865 & 3823 \\
\hline
\end{tabular}

\section{SIDE EFFECTS}

Any Extrapyramidal Symptoms Any Diabetes Any Abnormal Weight Gain Any Epilepsy

Any Cognitive or Motor Impairment Any Side Effects

$\begin{array}{lll}0.53 \% & 1.18 \% & 0.75 \% \\ 3.11 \% & 3.92 \% & 5.77 \% \\ 1.22 \% & 1.70 \% & 2.84 \% \\ 1.17 \% & 1.29 \% & 1.09 \% \\ 0.78 \% & 1.04 \% & 0.50 \% \\ 6.51 \% & 8.77 \% & 10.39 \%\end{array}$

$0.77 \%$
$3.43 \%$
$1.42 \%$
$0.86 \%$
$0.60 \%$
$6.78 \%$

$1.06 \%$

$0.80 \%$

$4.11 \% \quad 5.93 \%$

$2.46 \% \quad 3.09 \%$

$1.06 \% \quad 0.72 \%$

$0.82 \% \quad 0.32 \%$

$9.03 \% \quad 10.30 \%$ 
Table 5A: Diffusion of Risperdal, Zyprexa, and Seroquel

\begin{tabular}{|c|c|c|c|c|c|c|c|}
\hline \multirow[b]{2}{*}{ Year } & \multirow[b]{2}{*}{ Quarter } & \multicolumn{2}{|c|}{ Risperdal } & \multicolumn{2}{|c|}{ Zyprexa } & \multicolumn{2}{|c|}{ Seroquel } \\
\hline & & (1) & (2) & (3) & (4) & (5) & (6) \\
\hline 1994 & 1 & 38 & $0.6 \%$ & - & - & - & - \\
\hline 1994 & 2 & 339 & $5.7 \%$ & - & - & - & - \\
\hline 1994 & 3 & 220 & $3.7 \%$ & - & - & - & - \\
\hline 1994 & 4 & 254 & $4.2 \%$ & - & - & - & - \\
\hline 1995 & 1 & 284 & $4.7 \%$ & - & - & - & - \\
\hline 1995 & 2 & 314 & $5.2 \%$ & - & - & - & - \\
\hline 1995 & 3 & 328 & $5.4 \%$ & - & - & - & - \\
\hline 1995 & 4 & 344 & $5.6 \%$ & - & - & - & - \\
\hline 1996 & 1 & 363 & $5.9 \%$ & - & - & - & - \\
\hline 1996 & 2 & 383 & $6.2 \%$ & - & - & - & - \\
\hline 1996 & 3 & 409 & $6.6 \%$ & - & - & - & - \\
\hline 1996 & 4 & 440 & $7.2 \%$ & 81 & $1.3 \%$ & - & - \\
\hline 1997 & 1 & 428 & $6.9 \%$ & 163 & $2.6 \%$ & - & - \\
\hline 1997 & 2 & 445 & $7.3 \%$ & 229 & $3.7 \%$ & - & - \\
\hline 1997 & 3 & 477 & $7.8 \%$ & 292 & $4.7 \%$ & - & - \\
\hline 1997 & 4 & 575 & $9.4 \%$ & 605 & $9.9 \%$ & 7 & $0.1 \%$ \\
\hline 1998 & 1 & 615 & $10.1 \%$ & 761 & $12.5 \%$ & 21 & $0.3 \%$ \\
\hline 1998 & 2 & 659 & $10.8 \%$ & 893 & $14.7 \%$ & 82 & $1.3 \%$ \\
\hline 1998 & 3 & 682 & $11.1 \%$ & 968 & $15.7 \%$ & 115 & $1.9 \%$ \\
\hline 1998 & 4 & 722 & $11.8 \%$ & 1053 & $17.2 \%$ & 146 & $2.4 \%$ \\
\hline 1999 & 1 & 770 & $12.5 \%$ & 1118 & $18.1 \%$ & 173 & $2.8 \%$ \\
\hline 1999 & 2 & 834 & $13.6 \%$ & 1163 & $19.0 \%$ & 191 & $3.1 \%$ \\
\hline 1999 & 3 & 844 & $13.8 \%$ & 1189 & $19.5 \%$ & 214 & $3.5 \%$ \\
\hline 1999 & 4 & 862 & $14.2 \%$ & 1188 & $19.6 \%$ & 248 & $4.0 \%$ \\
\hline 2000 & 1 & 928 & $15.3 \%$ & 1221 & $20.2 \%$ & 281 & $4.6 \%$ \\
\hline 2000 & 2 & 952 & $16.0 \%$ & 1230 & $20.7 \%$ & 321 & $5.2 \%$ \\
\hline 2000 & 3 & 1010 & $16.9 \%$ & 1306 & $21.8 \%$ & 324 & $5.3 \%$ \\
\hline 2000 & 4 & 1050 & $17.6 \%$ & 1293 & $21.6 \%$ & 353 & $5.8 \%$ \\
\hline 2001 & 1 & 1072 & $17.9 \%$ & 1361 & $22.8 \%$ & 388 & $6.4 \%$ \\
\hline 2001 & 2 & 1123 & $18.8 \%$ & 1354 & $22.7 \%$ & 437 & $7.4 \%$ \\
\hline 2001 & 3 & 1100 & $18.5 \%$ & 1355 & $22.8 \%$ & 462 & $7.7 \%$ \\
\hline 2001 & 4 & 1123 & $19.0 \%$ & 1381 & $23.4 \%$ & 510 & $8.5 \%$ \\
\hline One & more & 3060 & (37.8\%) & 3173 & $(39.2 \%)$ & 1155 & $(14.3 \%)$ \\
\hline & & 5044 & (62.2\%) & 4931 & (60.8\%) & 6949 & (85.7\%) \\
\hline
\end{tabular}

Odd-numbered columns list \# of individuals in the sample with one or more claims for the drug.

Even-numbered columns provide the $\%$ of the sample with one or more claims for the drug.

Table 5B: \# with One or Multiple Drug Treatments

$\begin{array}{cc}\text { Group } & \text { Number } \\ \text { All Three } & 583 \\ \text { Risperdal, Zyprexa } & 1128 \\ \text { Risperdal, Seroquel } & 191 \\ \text { Zyprexa, Seroquel } & 205 \\ \text { Risperdal Only } & 1158 \\ \text { Zyprexa Only } & 1257 \\ \text { Seroquel Only } & 176 \\ \text { None of the Three } & 3406 \\ \text { Total } & 8104\end{array}$


Table 6: Distribution of the Number of Risperdal, Zyprexa, and Seroquel Prescriptions Filled in the Medicaid Sample

Risperdal

Schizoprhrenia Claim in:

$\begin{array}{cccc}\text { \# Scripts } & \text { 93Q1-93Q4 } & \text { All Others } & \text { Total } \\ 0 & 1928 & 3116 & 5044 \\ 1 & 156 & 277 & 433 \\ 2 & 85 & 162 & 247 \\ 3 & 65 & 113 & 178 \\ 4 & 61 & 109 & 170 \\ 5 & 49 & 89 & 138 \\ 6 & 32 & 75 & 107 \\ 7 & 43 & 63 & 106 \\ 8 & 32 & 50 & 82 \\ 9 & 32 & 64 & 96 \\ 10-14 & 122 & 194 & 316 \\ 15-19 & 105 & 148 & 253 \\ 20-29 & 139 & 160 & 299 \\ 30-39 & 113 & 107 & 220 \\ 40-49 & 65 & 66 & 131 \\ 50-59 & 54 & 30 & 84 \\ 60-69 & 45 & 22 & 67 \\ 70-79 & 24 & 13 & 37 \\ 80-89 & 29 & 15 & 44 \\ 90-99 & 21 & 5 & 26 \\ 100+ & 19 & 7 & 26 \\ \text { \# Obs } & 3219 & 4885 & 8104\end{array}$

\section{Zyprexa}

Schizoprhrenia Claim in:

95Q4-96Q3 All Others

1828

159

106

58

57

44

42

35

51

37

164

107

186

164

148

91

51

12

12

5

6
3363

$\begin{array}{cc}\text { All Others } & \text { Total } \\ 3103 & 4931 \\ 247 & 406 \\ 143 & 249 \\ 111 & 169 \\ 91 & 148 \\ 85 & 129 \\ 62 & 104 \\ 59 & 94 \\ 51 & 102 \\ 44 & 81 \\ 175 & 339 \\ 137 & 244 \\ 186 & 372 \\ 126 & 290 \\ 72 & 220 \\ 32 & 123 \\ 7 & 58 \\ 6 & 18 \\ 0 & 12 \\ 3 & 8 \\ 1 & 7 \\ 4741 & 8104\end{array}$

Schizoprhre
96Q4-97Q3
2963
96
60
42
39
32
28
17
25
16
60
54
58
42
12
14
2
1
2
1
1
3565

Seroquel

$\begin{array}{cc}\text { All Others } & \text { Total } \\ 3986 & 6949 \\ 115 & 211 \\ 69 & 129 \\ 39 & 81 \\ 41 & 80 \\ 29 & 61 \\ 35 & 63 \\ 28 & 45 \\ 18 & 43 \\ 14 & 30 \\ 59 & 119 \\ 32 & 86 \\ 45 & 103 \\ 17 & 59 \\ 7 & 19 \\ 2 & 16 \\ 2 & 4 \\ 0 & 1 \\ 1 & 3 \\ 0 & 1 \\ 0 & 1 \\ 4539 & 8104\end{array}$

First column for each drug gives distribution of \# of prescriptions among Medicaid recipients diagnosed with schizophrenia in the year before each drug hits the market, with the second column providing the distribution of the \# of prescriptions for all others in the sample. 
Table 7A: The Impact of Zyprexa Use on Medicaid Spending and Hospital / LTC Stays

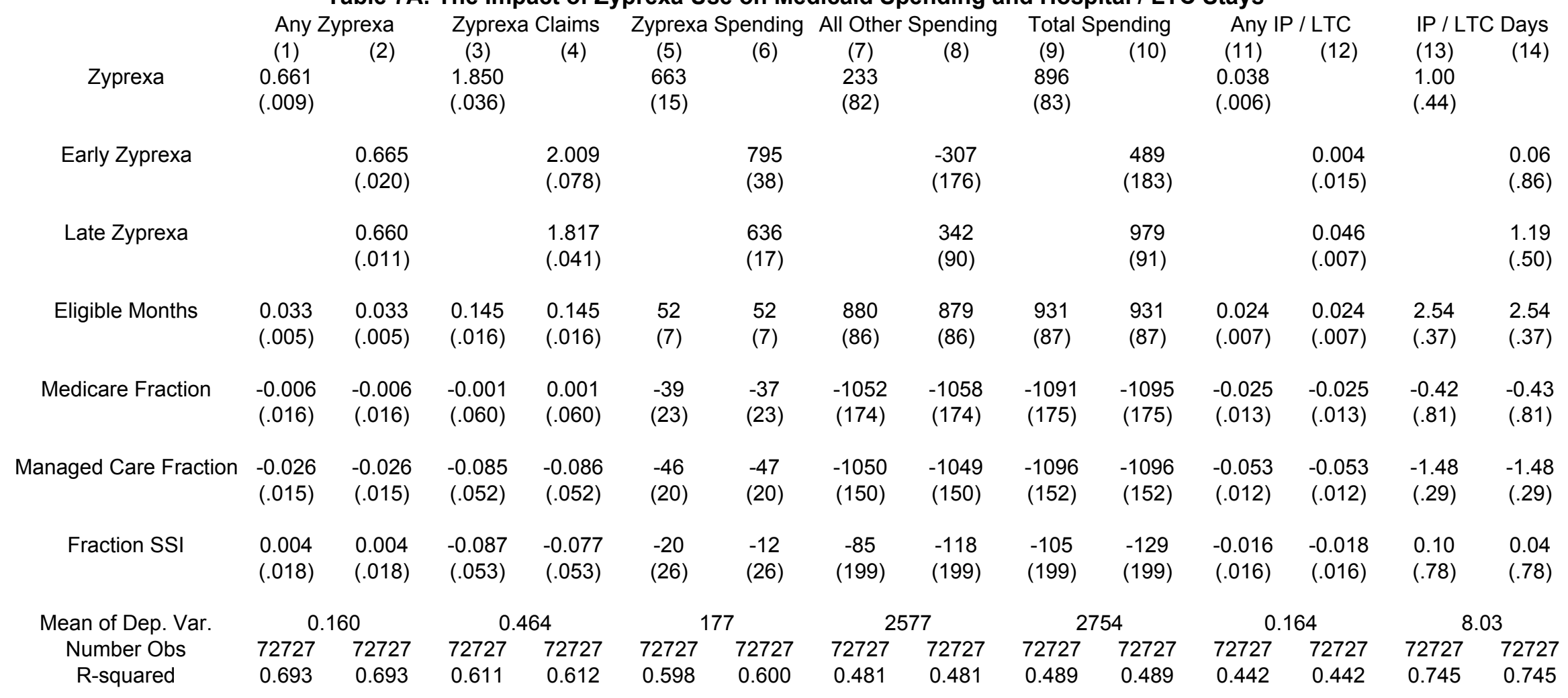

Sample includes all observations in the fourth quarter of 1995 or later for the 3363 individuals with one or more inpatient or outpatient Medicaid claims with a primary diagnosis of schizophrenia between October of 1995 and September of 1996 . Unit of observation is spending or utilization in one of the four quarters of each year. Thus the maximum number of observations for a person is 25 (1995Q4-2001Q4). All specifications include year*quarter and individual fixed effects. Zyprexa is an indicator variable equal to one if the person has one or more Zyprexa prescriptions in the current quarter or in any previous quarter and zero otherwise. Early Zyprexa is equal to this variable for individuals with a first Zyprexa prescription in or before September of 1997 and Late Zyprexa is equal to the Zyprexa indicator for all other individuals. Standard errors are in parentheses and are clustered by individual to account for serial correlation in the error term. 2286 of the 3363 individuals are 
Table 7B: The Impact of Risperdal Use on Medicaid Spending and Hospital / LTC Stays

\begin{tabular}{|c|c|c|c|c|c|c|c|c|c|c|c|c|c|c|}
\hline & \multicolumn{2}{|l|}{ Any $\mathrm{F}$} & \multicolumn{2}{|c|}{ Risperdal Claims } & \multicolumn{2}{|c|}{ Risperdal Spending } & \multicolumn{2}{|c|}{ All Other Spending } & \multicolumn{2}{|c|}{ Total Spending } & \multicolumn{2}{|c|}{ Any IP / LTC } & \multicolumn{2}{|c|}{ IP / LTC Days } \\
\hline isperdal & $\begin{array}{c}(1) \\
0.548 \\
(.011)\end{array}$ & $(2)$ & $\begin{array}{c}(3) \\
1.509 \\
(.037)\end{array}$ & (4) & $\begin{array}{l}(5) \\
372 \\
(11)\end{array}$ & (6) & $\begin{array}{c}(7) \\
351 \\
(99)\end{array}$ & $(8)$ & $\begin{array}{l}(9) \\
723 \\
(99)\end{array}$ & $(10)$ & $\begin{array}{c}(11) \\
0.040 \\
(.008)\end{array}$ & $(12)$ & $\begin{array}{l}(13) \\
2.16 \\
(.61)\end{array}$ & (14) \\
\hline Risperdal & & $\begin{array}{l}0.435 \\
(.019)\end{array}$ & & $\begin{array}{l}1.290 \\
(.066)\end{array}$ & & $\begin{array}{l}358 \\
(21)\end{array}$ & & $\begin{array}{c}24 \\
(226)\end{array}$ & & $\begin{array}{c}382 \\
(228)\end{array}$ & & $\begin{array}{l}0.000 \\
(.015)\end{array}$ & & $\begin{array}{c}-0.03 \\
(1.00)\end{array}$ \\
\hline Risperdal & & $\begin{array}{l}0.574 \\
(.012)\end{array}$ & & $\begin{array}{l}1.560 \\
(.043)\end{array}$ & & $\begin{array}{l}375 \\
(13)\end{array}$ & & $\begin{array}{c}427 \\
(111)\end{array}$ & & $\begin{array}{c}802 \\
(110)\end{array}$ & & $\begin{array}{l}0.049 \\
(.008)\end{array}$ & & $\begin{array}{l}2.67 \\
(.72)\end{array}$ \\
\hline of & & & & & & & & & & & & & & \\
\hline Th & 95900 & 95900 & 95900 & 95900 & 95900 & 95900 & 95900 & 959 & 95900 & 95 & 95900 & 95 & 95900 & 95900 \\
\hline -squared & 0.601 & 0.603 & 0.524 & 0.525 & 0.542 & 0.542 & 0.439 & 0.439 & 0.444 & 0.445 & 0.447 & 0.447 & 0.723 & 0.7 \\
\hline
\end{tabular}

Sample includes all observations for the 3219 individuals with one or more inpatient or outpatient Medicaid claims with a primary diagnosis of schizophrenia between January and December of 1993. Unit of observation is spending or utilization in one of the four quarters of each year. Thus the maximum number of observations for a person is 36 (1993Q1 - 2001Q4). All specifications include year*quarter and individual fixed effects. Risperdal is an indicator variable set equal to one if the person has one or more Risperdal prescriptions in the current quarter or any previous quarter and zero otherwise. Early Risperdal is equal to this variable for individuals with a first Risperdal prescription in 1994 and Late Risperdal is equal to the Risperdal indicator for all other individuals. Standard errors are in parentheses and are cluster by individual to account for serial correlation in the error term. 1911 of the 3219 individuals are observed in all 36 quarters.

Table 7C: The Impact of Seroquel Use on Medicaid Spending and Hospital / LTC Stays

\begin{tabular}{|c|c|c|c|c|c|c|c|c|c|c|c|c|c|c|}
\hline & \multicolumn{2}{|c|}{ Any Seroquel } & \multicolumn{2}{|c|}{ Seroquel Claims } & \multicolumn{2}{|c|}{ Seroquel Spending } & \multicolumn{2}{|c|}{ All Other Spending } & \multicolumn{2}{|c|}{ Total Spending } & \multicolumn{2}{|c|}{ Any IP / LTC } & \multicolumn{2}{|c|}{ IP / LTC Days } \\
\hline Seroquel & $\begin{array}{c}(1) \\
0.580 \\
(.015)\end{array}$ & (2) & $\begin{array}{c}(3) \\
1.695 \\
(.065)\end{array}$ & (4) & $\begin{array}{c}(5) \\
387 \\
(17)\end{array}$ & $(6)$ & $\begin{array}{c}(7) \\
558 \\
(139)\end{array}$ & (8) & $\begin{array}{c}(9) \\
945 \\
(139)\end{array}$ & (10) & $\begin{array}{c}(11) \\
0.060 \\
(.012)\end{array}$ & (12) & $\begin{array}{l}(13) \\
2.51 \\
(.83)\end{array}$ & $(14)$ \\
\hline Early Seroquel & & $\begin{array}{l}0.474 \\
(.033)\end{array}$ & & $\begin{array}{l}1.619 \\
(.144)\end{array}$ & & $\begin{array}{l}393 \\
(39)\end{array}$ & & $\begin{array}{c}493 \\
(277)\end{array}$ & & $\begin{array}{c}886 \\
(283)\end{array}$ & & $\begin{array}{l}0.060 \\
(.029)\end{array}$ & & $\begin{array}{c}3.47 \\
(2.10)\end{array}$ \\
\hline Late Seroquel & & $\begin{array}{l}0.606 \\
(.017)\end{array}$ & & $\begin{array}{l}1.714 \\
(.073)\end{array}$ & & $\begin{array}{l}386 \\
(20)\end{array}$ & & $\begin{array}{c}574 \\
(158)\end{array}$ & & $\begin{array}{c}960 \\
(158)\end{array}$ & & $\begin{array}{l}0.060 \\
(.013)\end{array}$ & & $\begin{array}{l}2.27 \\
(.90)\end{array}$ \\
\hline lean of Dep. Var. & & & & & & & & & & & & & & \\
\hline Number Obs & 65915 & 6591 & 65915 & 6591 & 65915 & 659 & 65915 & 65 & 65915 & & 65915 & & 65915 & 6591 \\
\hline R-squared & 0.634 & 0.637 & 0.530 & 0.530 & 0.508 & 0.508 & 0.502 & 0.502 & 0.504 & 0.504 & 0.460 & 0.460 & 0.760 & 0.76 \\
\hline
\end{tabular}

Sample includes all observations in the fourth quarter of 1996 or later for the 3565 individuals with one or more inpatient or outpatient Medicaid claims with a primary diagnosis of schizophrenia between October of 1996 and September of 1997. Unit of observation is spending or utilization in one of the four quarters of each year. Thus the maximum number of observations for a person is 21 (1996Q4 - 2001Q4). All specifications include year*quarter and individual fixed effects. Seroquel is an indicator variable set equal to one if the person has one or more Seroquel prescriptions in the current quarter or any previous quarter and zero otherwise. Early Seroquel is equal to this variable for individuals with a first Seroquel prescription in 1994 and Late Seroquel is equal to the Seroquel indicator for all other individuals. Standard errors are in parentheses and are cluster by individual to account for serial correlation in the error term. 2532 of the 3565 individuals are 
Table 8: The Impact of Zyprexa Use on Medicaid Spending and Hospital / LTC Stays - Early versus Late Adopters

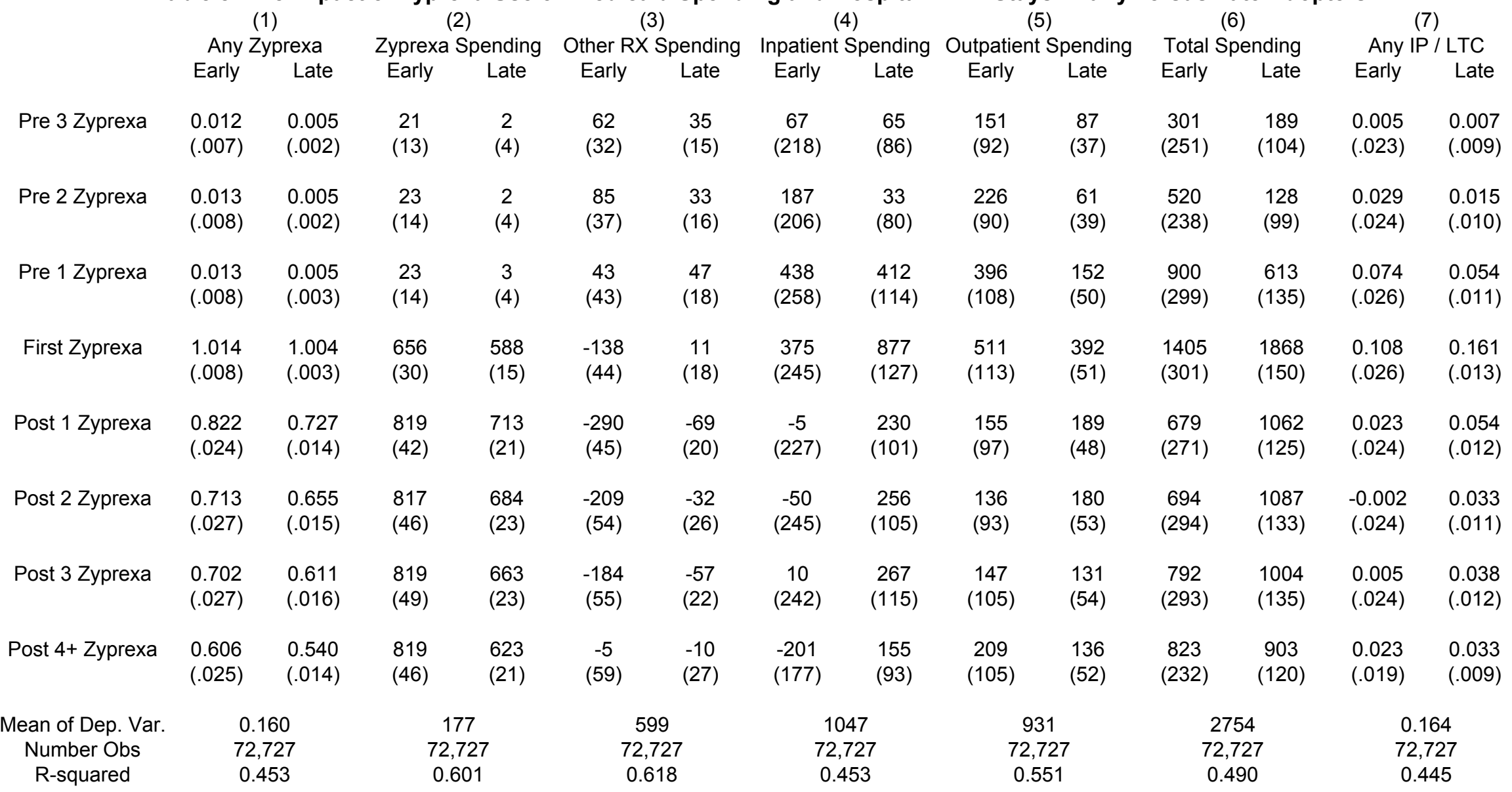

Sample includes all observations in the fourth quarter of 1995 or later for the 3363 individuals with one or more inpatient or outpatient Medicaid claims with a primary diagnosis of schizophrenia between October of 1995 and September of 1996. Unit of observation is spending or utilization in one of the four quarters of each year. Thus the maximum number of observations for a person is 25 (1995Q4-2001Q4). All specifications include year*quarter and individual fixed effects. First Zyprexa is an indicator variable equal to one in the first quarter that a person takes Zyprexa and zero otherwise. Pre (Post) $t$ Zyprexa is equal to one $t$ quarters before (after) the person's first Zyprexa prescription and zero otherwise. Standard errors are in parentheses and are clustered by individual to account for serial correlation in the error term. 2286 of the 3363 individuals are observed in all 25 quarters. 
Table 9: Atypical Anti-Psychotics and the Incidence of Adverse Side Effects

\begin{tabular}{|c|c|c|c|c|c|c|}
\hline & Extrapyramidal & Diabetes & Weight Gain & Epileptic Symptoms & Cog/Motor Impair. & Any Side Effec \\
\hline Early Zyprexa & $\begin{array}{l}0.0073 \\
(.0060)\end{array}$ & $\begin{array}{l}0.0020 \\
(.0075)\end{array}$ & $\begin{array}{r}-0.0038 \\
(.0055)\end{array}$ & $\begin{array}{l}0.0011 \\
(.0035)\end{array}$ & $\begin{array}{r}-0.0017 \\
(.0026)\end{array}$ & $\begin{array}{l}0.0034 \\
(.0113)\end{array}$ \\
\hline Late Zyprexa & $\begin{array}{l}0.0010 \\
(.0025)\end{array}$ & $\begin{array}{l}0.0122 \\
(.0043)\end{array}$ & $\begin{array}{l}-0.0043 \\
(.0031)\end{array}$ & $\begin{array}{l}-0.0008 \\
(.0018)\end{array}$ & $\begin{array}{l}0.0003 \\
(.0015)\end{array}$ & $\begin{array}{l}0.0096 \\
(.0058)\end{array}$ \\
\hline $\begin{array}{c}\text { R-squared } \\
\text { Mean of Dep. Var. } \\
\text { Number Obs. }\end{array}$ & $\begin{array}{l}0.332 \\
0.0094 \\
72727\end{array}$ & $\begin{array}{l}0.499 \\
0.0471 \\
72727\end{array}$ & $\begin{array}{l}0.184 \\
0.0216 \\
72727\end{array}$ & $\begin{array}{l}0.239 \\
0.0074 \\
72727\end{array}$ & $\begin{array}{l}0.236 \\
0.0052 \\
72727\end{array}$ & $\begin{array}{l}0.385 \\
0.0858 \\
72727\end{array}$ \\
\hline Early Risperdal & $\begin{array}{c}(1 \mathrm{~B}) \\
0.0064 \\
(.0061)\end{array}$ & $\begin{array}{c}(2 \mathrm{~B}) \\
-0.0006 \\
(.0052)\end{array}$ & $\begin{array}{c}(3 \mathrm{~B}) \\
0.0017 \\
(.0045)\end{array}$ & $\begin{array}{c}(4 \mathrm{~B}) \\
-0.0078 \\
(.0046)\end{array}$ & $\begin{array}{c}(5 \mathrm{~B}) \\
0.0089 \\
(.0036)\end{array}$ & $\begin{array}{c}(6 \mathrm{~B}) \\
0.0044 \\
(.0104)\end{array}$ \\
\hline Late Risperdal & $\begin{array}{l}0.0043 \\
(.0032)\end{array}$ & $\begin{array}{l}0.0089 \\
(.0044)\end{array}$ & $\begin{array}{l}0.0016 \\
(.0029)\end{array}$ & $\begin{array}{l}0.0025 \\
(.0019)\end{array}$ & $\begin{array}{l}0.0005 \\
(.0017)\end{array}$ & $\begin{array}{l}0.0168 \\
(.0063)\end{array}$ \\
\hline $\begin{array}{l}\text { R-squared } \\
\text { Mean of Dep. Var. } \\
\text { Number Obs. }\end{array}$ & $\begin{array}{l}0.317 \\
0.0106 \\
95900\end{array}$ & $\begin{array}{l}0.485 \\
0.0450 \\
95900\end{array}$ & $\begin{array}{l}0.143 \\
0.0177 \\
95900\end{array}$ & $\begin{array}{l}0.202 \\
0.0079 \\
95900\end{array}$ & $\begin{array}{l}0.166 \\
0.0046 \\
95900\end{array}$ & $\begin{array}{l}0.365 \\
0.0816 \\
95900\end{array}$ \\
\hline Early Seroquel & $\begin{array}{c}(1 \mathrm{C}) \\
0.0267 \\
(.0154)\end{array}$ & $\begin{array}{c}(2 \mathrm{C}) \\
0.0050 \\
(.0136)\end{array}$ & $\begin{array}{c}(3 C) \\
-0.0003 \\
(.0119)\end{array}$ & $\begin{array}{c}(4 C) \\
-0.0026 \\
(.0089)\end{array}$ & $\begin{array}{c}(5 C) \\
-0.0186 \\
(.0111)\end{array}$ & $\begin{array}{c}(6 C) \\
0.0110 \\
(.0250)\end{array}$ \\
\hline Late Seroquel & $\begin{array}{r}-0.0002 \\
(.0031)\end{array}$ & $\begin{array}{l}0.0148 \\
(.0069)\end{array}$ & $\begin{array}{l}-0.0054 \\
(.0042)\end{array}$ & $\begin{array}{l}0.0054 \\
(.0037)\end{array}$ & $\begin{array}{l}-0.0039 \\
(.0028)\end{array}$ & $\begin{array}{l}0.0144 \\
(.0090)\end{array}$ \\
\hline $\begin{array}{l}\text { R-squared } \\
\text { Mean of Dep. Var. } \\
\text { Number Obs. }\end{array}$ & $\begin{array}{l}0.356 \\
0.0091 \\
65915\end{array}$ & $\begin{array}{l}0.513 \\
0.0481 \\
65915\end{array}$ & $\begin{array}{l}0.176 \\
0.0220 \\
65915\end{array}$ & $\begin{array}{l}0.291 \\
0.0086 \\
65915\end{array}$ & $\begin{array}{l}0.312 \\
0.0055 \\
65915\end{array}$ & $\begin{array}{l}0.403 \\
0.0878 \\
65915\end{array}$ \\
\hline
\end{tabular}

This table summarizes the results for 18 different specifications ( 6 for each of the three drugs). Sample included for Zyprexa is the same as in Table 7A, while the Risperdal and Seroquel samples correspond to those used in Tables 7B and 7C, respectively. All specifications include year ${ }^{*}$ quarter and individual fixed effects. Extrapyramidal is equal to one if an individual has one or more claims with a primary diagnosis of EPS in the current quarter and zero otherwise. The other side effect variables are defined similarly. Standard errors are in parentheses and are 
Table 10A: Pre-Post Spending \& Utilization for Those Hospitalized w/Schz in 1994Q3

$\begin{array}{ccccccc}\text { Variable } & 1994 \mathrm{Q} 1 & 1994 \mathrm{Q} 2 & 1994 \mathrm{Q} 3 & 1994 \mathrm{Q} 4 & 1995 \mathrm{Q} 1 & 1995 \mathrm{Q} 2 \\ \text { Average Inpatient Days } & 4.65 & 7.22 & 16.84 & 7.59 & 4.75 & 3.67 \\ \text { Inpatient Spending } & \$ 2,827 & \$ 3,039 & \$ 8,337 & \$ 2,985 & \$ 1,595 & \$ 1,283 \\ \text { \% with 1+ Risperdal Scripts } & 1.1 \% & 17.0 \% & 14.8 \% & 12.6 \% & 13.5 \% & 16.7 \% \\ \% \text { with 1+ Zyprexa Scripts } & 0.0 \% & 0.0 \% & 0.0 \% & 0.0 \% & 0.0 \% & 0.0 \% \\ \text { \% with 1+ More Seroquel Script } & 0.0 \% & 0.0 \% & 0.0 \% & 0.0 \% & 0.0 \% & 0.0 \% \\ \text { \% with 1+ R, Z, S Scripts } & 1.1 \% & 17.0 \% & 14.8 \% & 12.6 \% & 13.5 \% & 16.7 \% \\ \text { Anti-Psychotic Drug Spending } & \$ 134 & \$ 231 & \$ 230 & \$ 226 & \$ 278 & \$ 314 \\ \text { Total Medicaid Spending } & \$ 4,416 & \$ 5,045 & \$ 10,757 & \$ 4,769 & \$ 3,555 & \$ 3,128 \\ \text { Number of Observations } & 184 & 188 & 196 & 191 & 185 & 186\end{array}$

Includes pre-post spending and utilization data for all 196 individuals hospitalized with a primary diagnosis of schizophrenia in the third quarter of 1994.

Table 10B: Pre-Post Spending \& Utilization for Those Hospitalized w/Schz in 2000Q3

$\begin{array}{ccccccc}\text { Variable } & 2000 \mathrm{Q} 1 & 2000 \mathrm{Q} 2 & 2000 \mathrm{Q} 3 & 2000 \mathrm{Q} & 2001 \mathrm{Q} 1 & 2001 \mathrm{Q} 2 \\ \text { Average Inpatient Days } & 6.72 & 7.38 & 17.90 & 6.93 & 6.41 & 6.79 \\ \text { Inpatient Spending } & \$ 2,130 & \$ 2,506 & \$ 4,707 & \$ 1,771 & \$ 1,605 & \$ 1,310 \\ \text { \% with 1+ Risperdal Scripts } & 18.6 \% & 16.8 \% & 23.0 \% & 25.2 \% & 26.6 \% & 30.9 \% \\ \% \text { with 1+ Zyprexa Scripts } & 34.8 \% & 33.6 \% & 43.0 \% & 38.9 \% & 41.1 \% & 37.7 \% \\ \text { \% with 1+ More Seroquel Script } & 12.2 \% & 12.7 \% & 16.6 \% & 14.1 \% & 15.3 \% & 15.7 \% \\ \text { \% with 1+ R, Z, S Scripts } & 55.7 \% & 53.6 \% & 66.0 \% & 67.1 \% & 69.4 \% & 67.3 \% \\ \text { Anti-Psychotic Drug Spending } & \$ 731 & \$ 677 & \$ 825 & \$ 904 & \$ 947 & \$ 944 \\ \text { Total Medicaid Spending } & \$ 4,844 & \$ 5,224 & \$ 8,252 & \$ 5,057 & \$ 4,923 & \$ 4,829 \\ \text { Number of Observations } & 221 & 220 & 235 & 234 & 229 & 223\end{array}$

Includes pre-post spending and utilization data for all 235 individuals hospitalized with a primary diagnosis of schizophrenia in the $t$ hird quarter of 2000.

Table 11: Distribution of Medicaid Spending for those w/1+ Schz Claims: 1994 \& 2001

\begin{tabular}{ccccccccccc} 
& \multicolumn{2}{c}{ Medicaid Spend } & \multicolumn{2}{c}{ Anti-Psych. Spend $\%$ w/1+ R,Z,S Script \% w/1+ IP/LTC Stay } & \multicolumn{3}{c}{ Any Side Effects? } \\
Decile & 1994 & 2001 & 1994 & 2001 & 1994 & 2001 & 1994 & 2001 & 1994 & 2001 \\
1 & $\$ 434$ & $\$ 779$ & $\$ 70$ & $\$ 183$ & $1.9 \%$ & $24.3 \%$ & $2.3 \%$ & $6.4 \%$ & $3.6 \%$ & $3.8 \%$ \\
2 & $\$ 1,080$ & $\$ 2,293$ & $\$ 163$ & $\$ 604$ & $4.9 \%$ & $49.3 \%$ & $5.2 \%$ & $14.1 \%$ & $5.5 \%$ & $12.1 \%$ \\
3 & $\$ 1,728$ & $\$ 3,766$ & $\$ 270$ & $\$ 1,215$ & $4.9 \%$ & $62.8 \%$ & $13.0 \%$ & $17.6 \%$ & $7.5 \%$ & $16.1 \%$ \\
4 & $\$ 2,459$ & $\$ 5,274$ & $\$ 374$ & $\$ 1,899$ & $8.4 \%$ & $72.1 \%$ & $13.6 \%$ & $18.4 \%$ & $8.7 \%$ & $15.9 \%$ \\
5 & $\$ 3,491$ & $\$ 7,213$ & $\$ 507$ & $\$ 2,612$ & $14.0 \%$ & $76.1 \%$ & $25.0 \%$ & $26.8 \%$ & $13.6 \%$ & $19.0 \%$ \\
6 & $\$ 5,048$ & $\$ 9,580$ & $\$ 833$ & $\$ 3,811$ & $19.8 \%$ & $78.7 \%$ & $35.7 \%$ & $33.7 \%$ & $14.6 \%$ & $22.8 \%$ \\
7 & $\$ 7,305$ & $\$ 12,633$ & $\$ 1,127$ & $\$ 4,484$ & $20.1 \%$ & $82.4 \%$ & $43.0 \%$ & $35.7 \%$ & $15.5 \%$ & $22.5 \%$ \\
8 & $\$ 11,281$ & $\$ 17,426$ & $\$ 1,843$ & $\$ 5,107$ & $15.6 \%$ & $83.6 \%$ & $56.8 \%$ & $51.0 \%$ & $16.6 \%$ & $24.5 \%$ \\
9 & $\$ 19,829$ & $\$ 27,004$ & $\$ 1,588$ & $\$ 4,530$ & $15.9 \%$ & $83.0 \%$ & $76.3 \%$ & $67.4 \%$ & $15.9 \%$ & $26.2 \%$ \\
10 & $\$ 45,075$ & $\$ 51,471$ & $\$ 1,044$ & $\$ 4,178$ & $19.4 \%$ & $85.3 \%$ & $95.5 \%$ & $89.1 \%$ & $24.6 \%$ & $30.8 \%$ \\
Mean & $\$ 9,781$ & $\$ 13,748$ & $\$ 782$ & $\$ 2,863$ & $12.5 \%$ & $69.8 \%$ & $36.7 \%$ & $36.0 \%$ & $12.6 \%$ & $19.4 \%$
\end{tabular}

Spending \& utilization data for the 3083 Medicaid recipients with one or more schizophrenia claims in 1994 and the 3469 in 2001. Individuals are grouped into deciles according to their Medicaid spending in 1994 or 2001. Thus for example \% w/1+ R,Z,S Scripts in 2001 for decile 7 gives the fraction of individuals in the 7 th decile of the expenditure distribution with one or more Risperdal, Zyprexa, or Seroquel prescriptions in that year. 
Table 12: The Effect of Psychiatrists on the Probability of Taking Zyprexa

Zyprexa in 1997

Psychiatrist Diff

\# Psych. Visits 95Q4-96Q3

Any IP Schiz. Claims 96Q3

\# IP Schiz. Claims 96Q3

Any OP Schiz Claims $96 Q 3$

Any OP Schiz Claims 96Q3

\# OP Schiz Claims 96Q3

Medicare

Elig. Months in 97,98, or $97-98$

Number Obs
Type of Illness Effects?
Age*Gender Effects?
(1)

(2)

1.994

(.238)

$\begin{array}{ll}0.005 & 0.005 \\ (.002) & (.002)\end{array}$

(.002)

$0.141 \quad 0.191$

(.083) (.098)

$-0.016 \quad-0.017$
$(.007)$

$\begin{array}{ll}(.007) \quad(.008) & 07)\end{array}$

$0.050 \quad 0.010$

(.077)

(.081)

$0.007 \quad 0.007$

(.002)

0.262

(.059)

0.081

(.033)

3011

Yes

Yes

$(.002)$

0.253

(.059)

$$
0.084
$$

(.031)

3011

Yes

Yes
Zyprexa in 1998

(3)

(4)

1.474

(.233)

$0.002 \quad 0.003$

(.002)

$(.002)$

0.169

(.077)

0.167

(.072)

$-0.004$

(.005)

$-0.003$

(.005)

0.135

(.068)

0.134

(.063)

0.003

(.002)

0.113

(.054)

0.086

(.019)

2995
Yes
Yes

Zyprexa in 97 or 98

(5)

(6)

1.563

$(.195)$

0.004

$\begin{array}{ll}(, 002) & (.002) \\ 0.154 & 0.156\end{array}$

(.076) (.077)

$-0.007 \quad-0.007$

$(.005) \quad(.005)$
0.119

$0.119 \quad 0.116$

(.067) (.059)

$0.003 \quad 0.006 \quad 0.006$

$\begin{array}{lll}(.002) \quad(.002) \quad(.002) & 0.00 \\ 0.113 & 0.145 & 0.145\end{array}$

$0.113 \quad 0.145 \quad 0.145$

$\begin{array}{lll}(.052) \quad(.053) \quad(.054) & 0.00\end{array}$

Sample includes individuals between the ages of 18-64 who visited a psychiatrist with a primary diagnosis of schizophrenia in the year before the release of Zyprexa. To be in the sample, individuals must also have been eligible for Medicaid in all three months of the third quarter of 1996, have never been eligible for Medicaid while residing in a COHS county, and be paired with a psychiatrist with at 15 patients in the sample. Dependent variable in each column is an indicator variable equal to one if the Medicaid recipient has one or more Zyprexa prescriptions in the time period and zero otherwise. Standard errors are in parentheses and are clustered by psychiatrist. 
Table 13: IV Estimates of the Effect of Zyprexa on Medicaid Spending

1997 Medicaid \$

1998 Medicaid \$

1997-98 Medicaid \$

(1)

Any Zyprexa 1997

4588

(5134)

Zyprexa Claims 1997

Any Zyprexa 1998

Zyprexa Claims 1998

Any Zyprexa 1997 or 1998

Zyprexa Claims 1997 and 1998

Spending 96Q3

Elig. Months in 97,98 ,or $97-98$

First Stage Estimate

Number Obs.

Type of Illness Effects?

Age ${ }^{\star}$ Gender Effects?

Mean of Dep. Var.

Corresponding OLS Est.
(2)

(3)

(4)

(5)

(6)
612

(688)

8521

(7021)

778

(541)

16280

(9017)

1134

(536)

\begin{tabular}{|c|c|c|c|c|c|}
\hline $\begin{array}{l}1.42 \\
(.17)\end{array}$ & $\begin{array}{l}1.42 \\
(.16)\end{array}$ & $\begin{array}{l}1.04 \\
(.15)\end{array}$ & $\begin{array}{l}1.03 \\
(.15)\end{array}$ & $\begin{array}{l}2.21 \\
(.27)\end{array}$ & $\begin{array}{l}2.21 \\
(.27)\end{array}$ \\
\hline $\begin{array}{c}896 \\
(197)\end{array}$ & $\begin{array}{c}897 \\
(200)\end{array}$ & $\begin{array}{c}933 \\
(188)\end{array}$ & $\begin{array}{c}911 \\
(185)\end{array}$ & $\begin{array}{c}478 \\
(193)\end{array}$ & $\begin{array}{c}450 \\
(195)\end{array}$ \\
\hline $\begin{array}{l}0.589 \\
(.070)\end{array}$ & $\begin{array}{l}4.42 \\
(.57)\end{array}$ & $\begin{array}{l}0.508 \\
(.073)\end{array}$ & $\begin{array}{l}5.57 \\
(.78)\end{array}$ & $\begin{array}{l}0.561 \\
(.070)\end{array}$ & $\begin{array}{c}8.05 \\
(1.06)\end{array}$ \\
\hline 2964 & 2964 & 2946 & 2946 & 2964 & 2964 \\
\hline Yes & Yes & Yes & Yes & Yes & Yes \\
\hline Yes & Yes & Yes & Yes & Yes & Yes \\
\hline \multicolumn{2}{|c|}{10694} & \multicolumn{2}{|c|}{11645} & \multicolumn{2}{|c|}{20701} \\
\hline $\begin{array}{l}4113 \\
(635)\end{array}$ & $\begin{array}{l}414 \\
(79)\end{array}$ & $\begin{array}{l}5671 \\
(620)\end{array}$ & $\begin{array}{l}476 \\
(57)\end{array}$ & $\begin{array}{l}9005 \\
(842)\end{array}$ & $\begin{array}{l}496 \\
(65)\end{array}$ \\
\hline
\end{tabular}

Sample includes individuals between the ages of 18-64 who visited a psychiatrist with a primary diagnosis of schizophrenia in the year before the release of Zyprexa. To be in the sample, individuals must also have been eligible for Medicaid in all three months of the third quarter of 1996, have never been eligible for Medicaid while residing in a COHS county, and be paired with a psychiatrist with at least 15 patients in the sample. Dependent variable in each column is total Medicaid spending in one of three time periods. In every equation, I instrument for Any Zyprexa (odd columns) or Zyprexa Claims (even columns) using the psychiatrist effects from Table12. First stage estimates are included as are the corresponding OLS estimates for coefficients on Any Zyprexa or Zyprexa claims. Standard errors are in parentheses and are clustered by psychiatrist. 


\begin{tabular}{|c|c|c|c|c|c|}
\hline & In Sample & Enter & Die & Leave & For Good \\
\hline 1993 Quarter 1 & 5653 & 5653 & 11 & 90 & 8 \\
\hline 1993 Quarter 2 & 5714 & 162 & 5 & 84 & 13 \\
\hline 1993 Quarter 3 & 5790 & 148 & 8 & 89 & 16 \\
\hline 1993 Quarter 4 & 5842 & 130 & 13 & 80 & 11 \\
\hline 1994 Quarter 1 & 5900 & 115 & 15 & 106 & 22 \\
\hline 1994 Quarter 2 & 5921 & 105 & 16 & 113 & 19 \\
\hline 1994 Quarter 3 & 5971 & 127 & 18 & 117 & 23 \\
\hline 1994 Quarter 4 & 5988 & 98 & 18 & 106 & 27 \\
\hline 1995 Quarter 1 & 6032 & 103 & 15 & 116 & 19 \\
\hline 1995 Quarter 2 & 6039 & 80 & 17 & 117 & 26 \\
\hline 1995 Quarter 3 & 6094 & 122 & 14 & 108 & 29 \\
\hline 1995 Quarter 4 & 6107 & 64 & 23 & 107 & 30 \\
\hline 1996 Quarter 1 & 6169 & 123 & 28 & 103 & 26 \\
\hline 1996 Quarter 2 & 6173 & 64 & 26 & 120 & 32 \\
\hline 1996 Quarter 3 & 6163 & 65 & 19 & 118 & 42 \\
\hline 1996 Quarter 4 & 6145 & 51 & 25 & 97 & 36 \\
\hline 1997 Quarter 1 & 6180 & 77 & 23 & 127 & 49 \\
\hline 1997 Quarter 2 & 6133 & 42 & 14 & 117 & 33 \\
\hline 1997 Quarter 3 & 6148 & 72 & 22 & 131 & 53 \\
\hline 1997 Quarter 4 & 6114 & 55 & 31 & 125 & 50 \\
\hline 1998 Quarter 1 & 6107 & 69 & 28 & 114 & 44 \\
\hline 1998 Quarter 2 & 6090 & 46 & 28 & 81 & 30 \\
\hline 1998 Quarter 3 & 6156 & 73 & 22 & 115 & 49 \\
\hline 1998 Quarter 4 & 6134 & 49 & 22 & 78 & 38 \\
\hline 1999 Quarter 1 & 6167 & 55 & 31 & 113 & 57 \\
\hline 1999 Quarter 2 & 6128 & 39 & 29 & 111 & 42 \\
\hline 1999 Quarter 3 & 6110 & 42 & 27 & 117 & 56 \\
\hline 1999 Quarter 4 & 6073 & 28 & 35 & 104 & 46 \\
\hline 2000 Quarter 1 & 6051 & 34 & 33 & 152 & 82 \\
\hline 2000 Quarter 2 & 5932 & 13 & 23 & 117 & 65 \\
\hline 2000 Quarter 3 & 5990 & 49 & 33 & 96 & 51 \\
\hline 2000 Quarter 4 & 5973 & 33 & 36 & 93 & 66 \\
\hline 2001 Quarter 1 & 5980 & 39 & 38 & 69 & 52 \\
\hline 2001 Quarter 2 & 5960 & 34 & 29 & 94 & 80 \\
\hline 2001 Quarter 3 & 5946 & 35 & 27 & 76 & 76 \\
\hline 2001 Quarter 4 & 5904 & 10 & 35 & - & - \\
\hline Total & 8104 & & 837 & & 1398 \\
\hline
\end{tabular}




\section{Appendix Table 2: Eligibility Info and \# Obs. for Medicaid Schizophrenia Samples}

Elig. Info for Those w/Schiz. In Yr Prior to Release of: \# Obs. for Those w/Schiz. In Yr Prior to Release of:

\begin{tabular}{|c|c|c|c|c|c|c|c|}
\hline $\begin{array}{c}\text { Eligible in: } \\
\text { 1993Q1 }\end{array}$ & $\begin{array}{c}\text { Risperdal } \\
3087\end{array}$ & $\begin{array}{c}\text { Zyprexa } \\
2734\end{array}$ & $\begin{array}{c}\text { Seroquel } \\
2791\end{array}$ & $\begin{array}{c}\text { \# Obs. } \\
1\end{array}$ & $\begin{array}{c}\text { Risperdal } \\
20\end{array}$ & $\begin{array}{c}\text { Zyprexa } \\
2\end{array}$ & $\begin{array}{c}\text { Seroquel } \\
2\end{array}$ \\
\hline 1993Q2 & 3109 & 2776 & 2829 & 2 & 21 & 8 & 3 \\
\hline 1993Q3 & 3118 & 2815 & 2859 & 3 & 30 & 4 & 9 \\
\hline 1993Q4 & 3102 & 2853 & 2896 & 4 & 22 & 10 & 10 \\
\hline 1994Q1 & 3067 & 2898 & 2943 & 5 & 35 & 8 & 12 \\
\hline 1994Q2 & 3012 & 2914 & 2959 & 6 & 34 & 9 & 11 \\
\hline 1994Q3 & 2969 & 2966 & 3002 & 7 & 39 & 6 & 6 \\
\hline 1994Q4 & 2934 & 2995 & 3035 & 8 & 36 & 13 & 8 \\
\hline 1995Q1 & 2892 & 3037 & 3065 & 9 & 28 & 15 & 12 \\
\hline 1995Q2 & 2860 & 3072 & 3094 & 10 & 29 & 13 & 10 \\
\hline 1995Q3 & 2828 & 3143 & 3148 & 11 & 32 & 12 & 14 \\
\hline 1995Q4 & 2808 & 3196 & 3186 & 12 & 30 & 19 & 12 \\
\hline 1996Q1 & 2786 & 3248 & 3255 & 13 & 41 & 38 & 22 \\
\hline 1996Q2 & 2747 & 3259 & 3311 & 14 & 35 & 35 & 16 \\
\hline 1996Q3 & 2714 & 3245 & 3365 & 15 & 25 & 36 & 17 \\
\hline 1996Q4 & 2694 & 3189 & 3416 & 16 & 30 & 30 & 25 \\
\hline 1997Q1 & 2675 & 3140 & 3451 & 17 & 44 & 43 & 40 \\
\hline 1997Q2 & 2636 & 3088 & 3444 & 18 & 24 & 26 & 47 \\
\hline 1997Q3 & 2625 & 3052 & 3432 & 19 & 32 & 47 & 58 \\
\hline 1997Q4 & 2608 & 3008 & 3359 & 20 & 46 & 44 & 61 \\
\hline 1998Q1 & 2570 & 2967 & 3308 & 21 & 33 & 36 & 60 \\
\hline 1998Q2 & 2540 & 2935 & 3261 & 22 & 27 & 48 & 60 \\
\hline 1998Q3 & 2537 & 2927 & 3242 & 23 & 24 & 49 & 55 \\
\hline 1998Q4 & 2513 & 2890 & 3196 & 24 & 31 & 66 & 87 \\
\hline 1999Q1 & 2500 & 2865 & 3181 & 25 & 28 & 58 & 52 \\
\hline 1999Q2 & 2464 & 2831 & 3134 & 26 & 37 & 68 & 78 \\
\hline 1999Q3 & 2447 & 2809 & 3097 & 27 & 35 & 60 & 67 \\
\hline 1999Q4 & 2430 & 2771 & 3060 & 28 & 40 & 54 & 63 \\
\hline 2000Q1 & 2414 & 2755 & 3031 & 29 & 36 & 60 & 70 \\
\hline 2000Q2 & 2378 & 2719 & 2977 & 30 & 35 & 71 & 82 \\
\hline 2000Q3 & 2356 & 2702 & 2953 & 31 & 46 & 76 & 84 \\
\hline $2000 Q 4$ & 2332 & 2677 & 2926 & 32 & 48 & 64 & 77 \\
\hline 2001Q1 & 2316 & 2650 & 2902 & 33 & 61 & 85 & 88 \\
\hline 2001Q2 & 2300 & 2629 & 2885 & 34 & 85 & 104 & 119 \\
\hline 2001Q3 & 2273 & 2592 & 2844 & 35 & 109 & 125 & 123 \\
\hline 2001Q4 & 2259 & 2583 & 2816 & 36 & 1911 & 1921 & 2005 \\
\hline Total & 95,900 & 104,930 & 111,653 & Total & 3219 & 3363 & 3565 \\
\hline
\end{tabular}

